\title{
Engineered Protein Coatings to Improve the Osseointegration of Dental and Orthopaedic Implants
}

Jordan Raphel ${ }^{I a}$, Johan Karlsson ${ }^{2 a}$, Silvia Galli ${ }^{3 a}$, Ann Wennerberg ${ }^{3}$, Christopher Lindsay, Matthew Haugh ${ }^{1}$, Jukka Pajarinen ${ }^{4}$, Stuart B. Goodman ${ }^{4}$, Ryo Jimbo ${ }^{3}$, Martin Andersson ${ }^{2}$, Sarah C. Heilshorn ${ }^{l} *$

${ }^{1}$ Department of Materials Science and Engineering, Stanford University, Stanford, CA, USA ${ }^{2}$ Department of Chemistry and Chemical Engineering, Chalmers University of Technology, Gothenburg, Sweden

${ }^{3}$ Department of Prosthodontics, Faculty of Odontology, Malmö University, Malmö, Sweden

${ }^{4}$ Department of Orthopaedic Surgery, Stanford University, Stanford, CA, USA

${ }^{a}$ Authors contributed equally to this work

Prof. S. Heilshorn

476 Lomita Mall

McCullough Rm 246

Stanford, CA

94305, USA

heilshorn@stanford.edu

fax: 650-498-5596

Keywords: engineered proteins, biomedical applications, functional coatings, hydrogels, tissue engineering

\begin{abstract}
Here we present the design of an engineered, elastin-like protein (ELP) that is chemically modified to enable stable coatings on the surfaces of titanium-based dental and orthopaedic implants by novel photocrosslinking and solution processing steps. The ELP includes an extended RGD sequence to confer bio-signaling and an elastin-like sequence for mechanical stability. ELP thin films were fabricated on cp-Ti and Ti6Al4V surfaces using scalable spin and dip coating processes with photoactive covalent crosslinking through a carbene insertion mechanism. The coatings withstood procedures mimicking dental screw and hip replacement stem implantations, a key metric for clinical translation. They promoted rapid adhesion of MG63 osteoblast-like cells, with over $80 \%$ adhesion after 24 hours, compared to $38 \%$ adhesion on uncoated Ti6Al4V. MG63 cells produced significantly more mineralization on ELP coatings compared to uncoated Ti6Al4V. Human bone marrow mesenchymal stem cells (hMSCs) had an earlier increase in alkaline phosphatase activity, indicating more rapid osteogenic differentiation and mineral deposition on
\end{abstract}


adhesive ELP coatings. Rat tibia and femur in vivo studies demonstrated that cell-adhesive ELPcoated implants increased bone-implant contact area and interfacial strength after one week. These results suggest that ELP coatings withstand surgical implantation and promote rapid osseointegration, enabling earlier implant loading and potentially preventing micromotion that leads to aseptic loosening and premature implant failure.

\section{Introduction}

Orthopaedic and dental implants have been widely employed for decades, with steep rises in use projected over the next $10+$ years as the population ages and life expectancy increases. ${ }^{[1,2]}$ However, up to $10 \%$ of these implants fail prematurely. ${ }^{[3-9]}$ The leading cause of failure for orthopaedic and dental implants is aseptic loosening of the implant from the surrounding bone tissue. ${ }^{[10-13]}$ A common hypothesis for aseptic loosening is that poor osseointegration at early times allows for micromotions of the implant relative to the bone. ${ }^{[14-18]}$ In the case of hips, knees, and teeth, these areas experience and transfer stresses during activities such as walking and chewing, which may lead to worsening of micromotions and ultimately result in the need for a revision surgery. Dental and orthopaedic implants are commonly made from titanium and titanium alloys, particularly Ti6A14V, due to their strong passivating oxide layer leading to good biocompatibility, resistance to corrosion, and well-suited mechanical properties. ${ }^{[19-22]}$ Many in the field have hypothesized that altering the implant surface or adding a coating to improve the osseointegration of the implant could improve stability in the short-term and ultimately reduce failures and revision surgeries in the long-term. ${ }^{[23-25]}$

Patients often begin load-bearing activities on their orthopaedic and dental implants immediately post-operation ${ }^{[26-29]}$, indicating that an ideal coating would initiate the process of osseointegration as early as possible. An ideal coating must fulfill three main requirements. First, it must be easily processable to be applied to implants of any shape and size. Second, it must be strongly adhered to and stable on the implant surface in order to survive the harsh implantation 
conditions and daily wear. Third, the coating should facilitate early osseointegration by encouraging

bone deposition on the implant surface and stabilizing the bone-implant interface. With these criteria in mind, researchers have sought to produce coatings using both extracellular matrix (ECM) proteins and small cell-binding peptides. ${ }^{[30,31]}$ However, issues regarding batch-to-batch reproducibility constrain the potential of naturally derived materials. ${ }^{[31,32]}$ Furthermore, directly tethering cell-binding peptides to the implant surface limits the methods that can be employed to modify other coating properties. Alternatively, recombinant protein based coatings are attractive as they retain the bioactivity of naturally derived materials, can be manufactured reproducibly, and are highly customizable. ${ }^{[32,33]}$

Here, we introduce a coating for titanium implants made from an engineered, photocrosslinkable, elastin-like protein (ELP) that provides each of these functionalities. ELPs are polypeptides based on the repetitive VPGXG amino acid sequence, where $\mathrm{X}$ is any residue other than proline. ${ }^{[34-36]}$ We chose to employ ELPs because they have been shown to be biocompatible and resilient polymers that can be produced and purified at scale. ${ }^{[37-46]}$ While ELP biomaterials have been developed for a broad range of potential drug delivery and soft tissue engineering applications ${ }^{[47-58]}$, they have only recently been explored for bone regeneration. Wang et al. utilized an ELP modified with octaglutamic acid motifs in order to bind hydroxyapatite (HAp), the main mineral component of bone, and to improve the mechanical properties of bone cement. ${ }^{[59]}$ Prieto et al. used ELP block copolymers to nucleate and grow HAp in simulated body fluid, achieving spherical, 1-3 nm HAp nanoparticles after 1 week. ${ }^{[60]}$ Both studies created novel ELP-based systems for bone composites in cell-free environments. Salvagni et al. previously demonstrated that ELP coatings can improve the in vitro alkaline phosphatase activity of human bone marrow mesenchymal stem cells (hMSCs) when tethered to titanium by organosilane chemistry. ${ }^{[61]}$ As polymer surface tethering may result in subsequent polymer "degrafting" upon exposure to external forces ${ }^{[62]}$ we sought to design an alternative coating mechanism that would be commercially scalable, reproducible, and able to withstand the large forces experienced during clinical 
implantation and wear. Specifically, we hypothesized that a photoreactive carbene insertion

mechanism could be used to form stable covalent bonds between the cell-instructive ELP thin films and the implant surface, thereby enhancing mineralization in vitro and in vivo.

Our ELP is a block copolymer interspersing elastin-like domains with bioactive RGD domains derived from an extended fibronectin sequence to enable biomimetic ligand presentation. ${ }^{[63]}$ This material is termed RGD ELP (Figure S1). As a control material, we employed a version of the ELP where the glycine and aspartic acid residues within the RGD sequence are scrambled ${ }^{[63]}$; this material is termed scrambled ELP (Figure S1). The ELP is modified with a photoreactive diazirine moiety to allow for UV-mediated crosslinking to form stable films. ${ }^{[33]}$ Previous analysis of our photocrosslinkable ELP thin films focused on in vitro cytocompatibility tests with human adipose-derived stem cells for general use in regenerative medicine therapies. ${ }^{[33]}$ In this work, we identify the carbene insertion mechanism as a novel strategy to create covalently crosslinked, mechanically stable protein thin films on metallic implants for orthopaedic and dental applications. In particular, we demonstrate the versatility of ELP thin films by using both spin and dip coating to form stable coatings on common implant materials (cp-Ti and Ti6Al4V) in a variety of geometries (discs, screws, and rods). Using a novel conjugation chemistry that enabled photocrosslinking of the ELP to itself and to the implant surface, these ELP coatings were able to withstand implantation procedures mimicking dental and orthopaedic implant surgeries. In vitro, the ELP coatings improved the rate of osteogenic differentiation and bone mineral deposition of hMSCs. In vivo, our ELP coating with an extended RGD sequence increased the bone-implant contact area and interfacial strength, key indicators of osseointegration, at early timepoints. Taken together, the obtained data suggest the clinical potential of these coatings for improved dental and orthopaedic implant performance.

\section{Materials and Methods}

\subsection{Recombinant Synthesis and Purification of ELP}


RGD ELP and scrambled ELP (Figure S1) were recombinantly expressed and purified as

previously reported ${ }^{[63]}$ Briefly, a plasmid encoding the RGD ELP or scrambled ELP protein sequence was transformed into an Escherichia coli host (BL21(DE3), New England Biolabs) and expression was induced by activating the T7-lac promoter with isopropyl $\beta$-D-1

thiogalactopyranoside (Sigma). After growth, the cells were lysed, and the target protein was purified by repeated centrifugation at alternating temperatures $\left(4^{\circ} \mathrm{C}\right.$ and $\left.37^{\circ} \mathrm{C}\right)$, utilizing the lower critical solution temperature of the ELP. ELP was dialyzed, lyophilized, and stored at $4{ }^{\circ} \mathrm{C}$.

\subsection{Diazirine Conjugation to ELP}

A heterobifunctional (N-hydroxy succinimide) ester diazrine crosslinker, (NHS-diazirine, succinimidyl 4,4'-azipentanoate, Pierce Biotechnology) was conjugated to the primary amines contained in ELP chains as previously reported. ${ }^{[33]}$ Briefly, the NHS-diazirine was dissolved in dimethyl sulfoxide $(0.5-1 \mathrm{~g} / \mathrm{mL})$ and mixed with a solution of ELP $(50 \mathrm{mg} / \mathrm{mL}$ in phosphate buffered saline (PBS)) to a final stoichiometric ratio of 1:1 functional groups. After reaction, the solution was dialyzed, lyophilized, and stored at $4{ }^{\circ} \mathrm{C}$. All subsequent references to ELP refer to this diazirine-modified photocrosslinkable form.

\subsection{Substrate Preparation}

Glass coverslips $(\mathrm{d}=12-\mathrm{mm}$, Azer Scientific) were rinsed in $70 \%$ ethanol and then dried with $\mathrm{N}_{2}$ gas. The coverslips were stored at $4{ }^{\circ} \mathrm{C}$ for 1 hour prior to ELP deposition. A Ti6Al4V sheet (1000 mm x $600 \mathrm{~mm} \times 1.60 \mathrm{~mm}$, Titanium Industries, Inc.) was fabricated into 12-mm diameter discs. The discs were wet grit-polished with successively finer levels of sandpaper (400, 600,1000 grit) prior to sonication in a series of $1 \%$ Triton X-100 in DI $\mathrm{H}_{2} \mathrm{O}$, acetone, $70 \%$ ethanol, and DI $\mathrm{H}_{2} \mathrm{O}$. The cleaned discs were dried with $\mathrm{N}_{2}$ gas and stored at $4{ }^{\circ} \mathrm{C}$. Ti6Al4V wire with diameter of $0.889 \mathrm{~mm}$ (Fort Wayne Metals) was cut to 10-mm lengths prior to undergoing the same 
cleaning and storage process outlined above for the Ti6A14V discs. cp-Ti dental screws (Neodent, Brazil) were submerged in $70 \%$ ethanol, dried with $\mathrm{N}_{2}$ gas, and stored at $4{ }^{\circ} \mathrm{C}$.

\subsection{Processing of ELP Coatings}

Spin coated ELP films were prepared from $50 \mathrm{mg} / \mathrm{mL}$ (5 wt.\%) solutions of ELP dissolved in $1 \mathrm{x}$ PBS at $4{ }^{\circ} \mathrm{C}$. Substrates were placed on the stage of a spin coater (WS-400-6NPP, Laurell Technologies), then the protein solution was applied to the substrate surface and spread with the pipette tip to gain complete surface coverage. The substrate was then spun at 4,000 rpm for $90 \mathrm{~s}$. For glass coverslips, $14 \mu \mathrm{L}$ of ELP solution was added per substrate. For Ti6A14V discs, $7 \mu \mathrm{L}$ of ELP solution was added per substrate. After spin coating, samples were crosslinked with ultraviolet (UV) light using a $365 \mathrm{~nm}, 8$ Watt light source (3UV-38, UVP) at a distance of approximately $5 \mathrm{~cm}$ for 1 hour. For Ti6A14V discs, a second spin coating layer of $7 \mu \mathrm{L}$ of ELP solution was applied, followed by a second UV crosslinking step. Cp-Ti dental screws were spin coated under the same conditions using $40 \mu \mathrm{L}$ of ELP solution.

Dip coated ELP films were also prepared from $50 \mathrm{mg} / \mathrm{mL}$ ( $5 \mathrm{wt} . \%)$ solutions of ELP dissolved in $1 \mathrm{x}$ PBS at $4{ }^{\circ} \mathrm{C}$. The ELP solution was then placed into a trough custom fabricated using 3D printing (Figure S2). 12-mm glass coverslips, 12-mm Ti6A14V discs, or 10-mm Ti6A14V rods were loaded into a custom, 3D-printed holder attached to a dip coater (Figure S2). Samples were lowered at $1 \mathrm{~mm} / \mathrm{s}$ into the ELP solution, held for $30 \mathrm{~s}$, and then withdrawn at removal speeds between $0.25 \mathrm{~mm} / \mathrm{s}$ and $10 \mathrm{~mm} / \mathrm{s}$. Samples were then UV crosslinked under the same conditions described above. After UV crosslinking, both spin and dip coated samples were rinsed in 1x PBS for 1 hour, rocking, at room temperature in order to remove any unbound ELP prior to further experiments.

\subsection{Coating Thickness Measurements}


ELP film heights were measured using profilometry. Samples were scratched prior to being

placed on the stage of the profilometer (Dektak 150, Bruker). Samples were scanned between 1-5 $\mathrm{mm}$ in length for between 10-60 seconds and with a tip force between 5-15 $\mu \mathrm{g}$. Film height was determined by finding the average step height between a selected region of the coating and a selected region of the scratched area. A minimum of 2 samples were tested with a minimum of 3 scans per sample.

\subsection{Film Stability in Solution}

Photocrosslinked ELP samples were rinsed for given periods of time in 1x PBS in a $37^{\circ} \mathrm{C}$ incubator. Non-UV treated ELP films were used to measure the initial amount of protein deposition. Samples were then removed from the wash solution and placed in fresh wells. The mass of retained protein was determined by a bicinchoninic acid (BCA) assay (QuantiPro, Sigma Aldrich). The samples were submerged in $500 \mu \mathrm{L}$ of 1x PBS, followed by the addition of $500 \mu \mathrm{L}$ of BCA reagent (25:25:1 QA buffer:QB buffer:copper II sulfate solution). The reaction was incubated at $60{ }^{\circ} \mathrm{C}$ for 1 $\mathrm{hr}$, equilibrated at room temperature for $20 \mathrm{~min}$, and quantified by absorbance at $562 \mathrm{~nm}$ for comparison to a standard curve of ELP in solution.

\subsection{Contact Angle Measurement}

Contact angle of DI $\mathrm{H}_{2} \mathrm{O}$ on Ti6A14V discs was measured using a goniometer (Rame-Hart 290) using $15 \mu \mathrm{L}$ of DI $\mathrm{H}_{2} \mathrm{O}$. The discs were either untreated or had been spin coated with $14 \mu \mathrm{L} 1 \mathrm{x}$ PBS and exposed to UV light for 1 hour. 10\% benzoyl chloride (Sigma) solution in dimethylformamide (DMF) was added to the surface of the discs for 1 hour. The samples were rinsed 3 times with DMF prior to drying with $\mathrm{N}_{2}$ gas.

\subsection{Film Stability on Implants}


Spin coated cp-Ti dental screws were screwed into a synthetic bone mimic (10 PCF

polyurethane foam block, Sawbones) and then extracted via unscrewing. The screws were imaged via scanning electron microscopy (SEM) before implantation and after extraction.

The stability of ELP coatings dip coated onto Ti6Al4V rods was determined as previously reported. ${ }^{[64]}$ Briefly, Ti6A14V rods were dip coated in a 5 wt.\% ELP solution containing $0.15 \%$ wt.\% ELP fluorescently labeled with rhodamine B isothiocyanate (Sigma). The intercondylar notch of cadaver mouse femurs was opened with successively larger needles ranging from 25-21 gauge to create a drill-hole reaching the medullary cavity. Rods were then manually press-fit into the medullary cavity. The rod was removed by creating a superficial, longitudinal incision in the femur and lifting the rod out. Images of the coated rods pre- and post-implantation were taken on a transillumintaor (ChemiDoc MP, Bio-Rad) and confocal microscope (Leica SPE) using a rhodamine filter. The fluorescence intensity was quantified by measuring average pixel intensity in ImageJ (National Institutes of Health, Bethesda, MD, USA). 8 rods were implanted and imaged, with three images taken per rod.

\subsection{Scanning Electron Microscopy (SEM) Characterization}

SEM samples were prepared using the above protocols. Samples were then crosslinked in 4\% paraformaldehyde for $15-60$ minutes prior to undergoing graded ethanol dehydration $(30 \%$, $50 \%, 70 \%, 90 \%$, and two $100 \%$ ethanol rinses for 10 min each). The samples then underwent critical point drying (Autosamdri-815, Tousimis) in $\mathrm{CO}_{2}$ prior to gold-palladium sputter coating. Dental screw micrographs were obtained on a variable-pressure SEM (Hitachi S-3400N Variable Pressure SEM, operated at $15 \mathrm{kV}$, pressure 50-60 Pa, using a Deben Coolstage for temperature control). All other micrographs were obtained on a field emission SEM (Zeiss Sigma FESEM, operated at $2-3 \mathrm{kV})$.

\subsection{MG63 Cell Culture}


MG63 human osteoblast-like cells (CRL-1427, ATCC) were obtained, thawed, and

passaged according to supplier recommendations. Briefly, cells were grown in EMEM medium (Fisher) supplemented with 10\% heat-inactivated fetal bovine serum (FBS), $1 \%$ penicillin/streptomycin at $37{ }^{\circ} \mathrm{C}$ with $5 \%$ atmospheric $\mathrm{CO}_{2}$. Cells were passaged using $0.25 \%$ trypsin-EDTA (1x). For mineralization studies, the MG63 medium was supplemented with $8 \mathrm{mM}$ $\mathrm{CaCl}_{2}$ (Sigma). Cells were seeded at $2.375 \times 10^{4}$ cells/disc onto $12-\mathrm{mm}$ substrates in 24 well plates. Media was changed every other day.

\subsection{1 hMSC Cell Culture}

Human, bone marrow-derived mesenchymal stem cells (PT-2501, Lonza) were obtained, thawed, and passaged according to supplier recommendations. Briefly, cells were grown in DMEM medium supplemented with $10 \% \mathrm{FBS}, 2 \%$ penicillin/streptomycin, and $1 \%$ Glutamax at $37^{\circ} \mathrm{C}$ with $5 \%$ atmospheric $\mathrm{CO}_{2}$. Osteogenic studies used additional supplements of $100 \mathrm{nM}$ dexamethasone, $50 \mu \mathrm{g} / \mathrm{mL}$ ascorbic acid, and $10 \mathrm{mM} \beta$-glycerophosphate. Cells were passaged using $0.25 \%$ trypsinEDTA (1x). Cells were seeded at 1x10 $0^{4}$ cells/coverslip onto 12-mm glass coverslips in 24 well plates. Media was changed every 3-4 days.

\subsection{Cell Spreading Analysis}

Spreading of cells seeded onto transparent glass coverslips was quantified by phase contrast microscopy on an inverted microscope (Axiovert, Zeiss). Coverslips were pre-marked with a grid template. Adhesion counts were taken at four pre-defined locations on the grid per sample $(\mathrm{n}=3)$. Spread cells were defined as those which lacked a refractory halo and were non-spherical in appearance ${ }^{[33]}$ Cultures were fixed overnight in $4 \%$ paraformaldehyde and blocked with $10 \%$ normal goat serum or FBS containing $0.1 \% \mathrm{v} / \mathrm{v}$ Triton X-100 in 1x PBS for 1 hour at room temperature. After rinsing, samples were stained with 6-diamidino-2-phenylindole (DAPI, $2 \mu \mathrm{g} / \mathrm{ml}$, 
Roche) to visualize cell nuclei and with rhodamine-conjugated phalloidin (1:200 dilution,

Invitrogen) to visualize F-actin. Fluorescent images were obtained with a confocal microscope.

\subsection{Cell Adhesion Analysis}

Adhesion onto Ti6A14V substrates was quantified by assaying the amount of DNA per sample. Briefly, the samples were rinsed in 1x PBS to remove non-adhered cells, transferring the substrates to fresh wells, and lysing in a buffer containing $10 \mathrm{mM}$ Tris, $1 \mathrm{mM} \mathrm{MgCl}, 20 \mu \mathrm{M} \mathrm{ZnCl}_{2}$, and $0.02 \%$ Triton $\mathrm{X}-100$ in $\mathrm{DI} \mathrm{H}_{2} \mathrm{O}$. The samples were then frozen at $-20{ }^{\circ} \mathrm{C}$, thawed, and processed according to the instructions of the PicoGreen assay kit (Quant-iT PicoGreen dsDNA assay kit, Life Technologies). The quantity of dsDNA was correlated to a cell number by creating a cell number standard curve, relating PicoGreen fluorescent signal to known numbers of cells. The percentage of cells adhered was then calculated by dividing the amount of dsDNA detected in the samples by the total amount of dsDNA for the seeded cells.

\subsection{Mineralization Assay}

Seeded substrates were moved to fresh wells and rinsed twice with $1 \mathrm{x}$ PBS. $1 \mathrm{~mL}$ of $0.5 \mathrm{~N}$ $\mathrm{HCl}$ was added to each well, and plates were put on a rocker overnight at room temperature. Calcium content was quantified using the Calcium (CPC) Liquicolor Test (0150-250, Stanbio). Briefly, aliquots of the $\mathrm{HCl}$ wash were added to a working reagent and allowed to react for $5 \mathrm{~min}$ at room temperature prior to measuring the absorbance at $550 \mathrm{~nm}$. A standard curve of calcium in $\mathrm{HCl}$ diluted with the same working reagent was created to correlate absorbance values with calcium content reported in total calcium deposited per sample. For mineralization assays, $n=4$ per condition, and each sample was assayed in triplicate.

\subsection{Alkaline Phosphatase Assay}


Intracellular alkaline phosphatase (ALP) was assayed using the SIGMAFAST p-nitrophenyl

phosphate tablets kit (p-NPP kit, Sigma). Briefly, substrates were placed in $1 \mathrm{~mL}$ of the same lysis buffer used to quantify cell DNA content. The cell lysate was then mixed with $5 \mathrm{mM}$ p-NPP. This same $5 \mathrm{mM}$ p-NPP solution mixed with an ALP enzyme solution and serially diluted to make a standard curve. All samples were incubated for 1 hour in the dark at room temperature. A $3 \mathrm{M}$ $\mathrm{NaOH}$ stop solution was added to each well before the $405 \mathrm{~nm}$ absorbance was read. The data are reported as ALP activity normalized to DNA concentration to provide an indication of differentiation on a per cell basis.

\subsection{In Vivo Study}

\subsubsection{Endotoxin Purification}

ELP underwent endotoxin purification prior to use in live rodent studies to remove residual lipopolysaccharide from protein expression. Briefly, ELP was dissolved at $10 \mathrm{wt}$ \% in a 9\% formic acid solution and heated to $100^{\circ} \mathrm{C}$ for 30 minutes. The solution was then diluted 5 -fold in deionized water prior to freezing at $-80{ }^{\circ} \mathrm{C}$ and lyophilization. The ELP was then resolubilized at $5 \mathrm{wt}$. \% in deionized water and centrifuged at $4{ }^{\circ} \mathrm{C}$ for 1 hour at $10,000 \mathrm{rpm}$. The supernatant was transferred to a fresh tube, and sodium chloride was added to a final concentration of $0.3 \mathrm{M}$. The solution was then centrifuged at $37^{\circ} \mathrm{C}$ for 1 hour at $10,000 \mathrm{rpm}$. The pellet was resuspended in deionized water, dialyzed, frozen, and lyophilized prior to resuspension for spin coating onto cp-Ti screws. Endotoxin levels were quantified using the PyroGene rFC assay kit (Lonza) following manufacturer's instructions. Final endotoxin levels of RGD ELP and Scrambled ELP were 0.1 $\mathrm{EU} / \mathrm{ml}$, below the FDA limit of $0.5 \mathrm{EU} / \mathrm{ml}$ (Figure S3). ${ }^{[65]}$

\subsubsection{Animal Study}

The endotoxin purified ELP coatings were evaluated in an in vivo rodent study. Three sample groups were included in the study; RGD ELP, scrambled ELP and uncoated Ti screws. The 
RGD ELP and the scrambled ELP were deposited onto the Ti screws according to the procedure

described above in the sections of Substrate Preparation and Processing of ELP Coatings. Twentyfour female Sprague-Dawley rats weighing in average $250 \mathrm{~g}$ (age 12 weeks) were used as animal model. The implants were inserted bilaterally in proximal and distal sites of each tibial metaphysis and in the femoral distal metaphysis. Prior to surgery, the animals were induced anesthesia with a mixture of ketamine (Imalgène $1000^{\circledR}$, Merial, Sanofi, France) and medetomidine (Domitor ${ }^{\circledR}$, Zoetis, France) in a dose of $0.2 \mathrm{ml} / 100 \mathrm{~g}$ administrated intra-peritoneum. Potentiation of anesthesia was obtained with sub-cutaneous administration of $0.1 \mathrm{ml} / 100 \mathrm{~g}$ of buprenorphine (Buprécare, Animalcare, UK). During the whole procedure the rats were perfused with $\mathrm{NaCl} 0.9 \%$, and allowed to breath spontaneously with support of $100 \% \mathrm{O}_{2}$ and their oxygen saturation in blood and cardiac frequency were constantly monitored. Screw installation sites were prepared in sequence with $\varnothing 1.4$ $\mathrm{mm}, 1.8 \mathrm{~mm}$ and $2 \mathrm{~mm}$ round burs, followed by final tapping of the osteotomies, under constant perfusion of $0.9 \% \mathrm{NaCl}$. The four-stage drilling procedure was performed to avoid excess heat formation and to lower the risk of unforeseen fractures or other means of compromising bone quality. The implants were screwed into the pre-drilled holes in the tibia and femur and the subcutaneous wound was closed with resorbable sutures (5-0, vicryl, Ethicon, Johnson \& Johnson, Brussels, Belgium) and skin with non-resorbable sutures (4-0, Ethilon, Johnson \& Johnsson). Immediately after surgery the rats were treated with analgesic therapy intramuscularly injected at $0.1 \mathrm{ml} / 100 \mathrm{~g}$ (Meloxicam, Metacam, Boehringer Ingelheim Vetmedica Inc., US), then supported for the next 3 days. Antibiotics were administrated orally for 5 days. The animals were grouped housed (three per cage) and allowed free postoperative movements with food and water ad libitum. Prior to explantation, animals were anesthetized and subsequently given an overdose of pentobarbital/saline (1:1) at $10 \mathrm{~mL} / \mathrm{kg}$. The samples were harvested at three different time-points; one, four and eight weeks. Non-decalcified histology and screw removal torque biomechanical testing were performed for the in vivo evaluation of the different samples. The animal study was approved by the ethical 
committee for animal experiments at the Ecole Nationale Veterinaire D'Alfort, Maisons-Alfort, France, and it was conducted taking the highest care to minimize animal pain and discomfort.

\subsubsection{Histomorphometry}

The implants were retrieved with surrounding bone for histomorphmetric evaluation. Boneimplant contact (BIC) measurements were performed to compare the groups of RGD ELP, scrambled ELP and uncoated Ti screws after one, four and eight weeks of healing ( $\mathrm{n}=8$ samples per group and per healing time). The retrieved bone blocs were fixated and dehydrated in ascending ethanol concentrations. Thereafter, the samples were infiltrated with 2-hydroxyethyl methacrylate light-curing resin (Technovit 7200 VLC, Heraeus Kulzer, Wehrheim, Germany) and finally embedded in the same plastic resin. The samples were then cut along the longitudinal axis of the implants utilizing an Exakt saw (EXACT ${ }^{\circledR}$ Apparatebau, Norderstedt, Germany) and ground to obtain sections with a thickness of $20-30 \mu \mathrm{m}$. The sections were subsequently stained with toluidine blue prior to analysis. Images of the specimens were captured with a light microscope (Eclipse ME600; Nikon, Tokyo, Japan). Quantitative measurements of the BIC in the captured images were performed using ImageJ. The amount of bone-matrix in direct contact with the implant surface was quantified in each slide and it was then calculated as percentage over the total surface of the implant, as visible on each slide. Direct contact was considered when between the bone matrix and the implant surface there was no visible space and the matrix was adherent to the surface. All the measurements where performed on images at 100X magnification. The quantification was done by one expert operator, who measured all the implants and was blinded to the different sample groups.

\subsubsection{Biomechanical Analysis}

The implants in the femur were analyzed with removal torque (RTQ) quantification. Immediately after animal euthanasia, the skin and the muscles were dissected and the torque needed 
to loosen the screws from the surrounding bone was recorded with a digital torque gauge (Tohnichi,

Tokio, Japan). The values were recorded as $\mathrm{N} / \mathrm{cm}^{2}$ and were used to describe the strength of the interface between the implant surfaces and the bone.

\subsection{Statistics}

Analysis was done using one-way ANOVA (GraphPad Prism) followed by Tukey's multiple comparison test when appropriate. A p-value of $<0.05$ was considered significant.

\section{Results and Discussion}

\subsection{Stable ELP Coatings are Chemically Conjugated to Titanium-based Implant Surfaces}

Orthopaedic and dental implants come in a variety of sizes and geometries, from cylindrical screws to asymmetric hip and knee prostheses. Our first goal was to create easily processable and stable coatings that could be fabricated directly on the surface of any of these implants. This required a versatile material that could be processed by multiple deposition techniques to accommodate a range of implant geometries. While spin coat processing is feasible for smaller, symmetric implants such as dental screws, dip coat processing is useful for larger and asymmetric implants such as hip and knee prostheses. Therefore, we sought to demonstrate that both spin and dip coating of photocrosslinkable ELP could be successfully used to coat Ti6A14V, a common dental and orthopaedic implant material.

We synthesized and purified photocrosslinkable ELP as previously described. As previously reported, using an E. coli expression host, we were able to produce large quantities $(1 \mathrm{~g}$ purified ELP/12 L expression) of our recombinant ELP in a scalable manner. The photocrosslinkable ELP was solubilized in a buffered saline, aqueous solution and deposited at $4{ }^{\circ} \mathrm{C}$ via either spin or dip coating (Figure S4). As expected, the thickness of the ELP coating was tunable by altering the processing conditions. For spin coated films, the thickness was linearly increased by spin coating successive ELP layers after photocrosslinking. The base coating layer was approximately $80 \mathrm{~nm}$ in 
height, with each additional layer increasing total thickness by an average of $65 \mathrm{~nm}$ per layer. For

dip coated films, thicker films were obtained by increasing the removal speed from the ELP bath, as expected. ${ }^{[66]}$ Removing the samples at $1 \mathrm{~mm} / \mathrm{s}$, the speed used for the remainder of our experiments, resulted in a thickness of $110 \mathrm{~nm}$. For both processing methods, no significant difference in thickness was found between scrambled and RGD ELP coatings. The ability to tune the thickness of the ELP coatings could allow for specific or customized coatings to be applied to implants, with thicker coatings being employed for gap-filling applications and thinner coatings maintaining underlying surface nanotopography, a physical characteristic found to be important in osseointegration. ${ }^{[67]}$

The next coating requirement is to form a strong and stable interface with the implant surface, as many coating technologies lead to weakly adhered coatings that can delaminate. ${ }^{[19,68-71]}$ Elastin is a tough and resilient protein ${ }^{[72]}$, and we hypothesized that covalent conjugation of the ELP coating to the metallic surface would be able to withstand the clinical stresses experienced during implantation. Based on the literature, we proposed a covalent conjugation mechanism whereby pendant diazirines on ELP form activated carbenes upon UV exposure that are able to interpose into the O-H bonds present at titanium surfaces (Figure 1A). ${ }^{[73,74]}$ Furthermore, titanium surface hydroxyls have been shown to increase with exposure to UV light, thereby presenting more sites for covalent ELP conjugation. ${ }^{[75]}$ To explore this hypothesis, surface contact angle measurements were performed on Ti6A14V substrates irradiated with UV light in the presence of phosphate buffered saline (PBS). This UV exposure resulted in a significant increase in surface hydrophilicity, with the contact angle decreasing from $50.83^{\circ}$ to $26.33^{\circ}$, consistent with an increase in surface hydroxyls (Figure 1B, top). Samples were then exposed to a 10\% benzoyl chloride solution, a hydrophobic reagent that covalently reacts with hydroxyl groups. Ti6Al4V discs that had not been previously exposed to UV light showed no significant change in contact angle, implying the benzoyl chloride was unable to sufficiently couple to the surface due to a low concentration of surface hydroxyls. However, samples with UV exposure became significantly more hydrophobic upon reaction with 
benzoyl chloride, confirming that UV exposure increases surface hydroxyl concentration (Figure

$1 \mathrm{~B}$, bottom). This result suggests that UV exposure can increase the surface hydroxyl content of titanium-based substrates.

Our photocrosslinking reaction involves the generation of highly reactive carbene intermediates from diazirine moities activated by exposure to UV light. ${ }^{[76]}$ These carbenes are then able to interpose themselves into heteroatom-H or C-H bonds ${ }^{[77]}$, allowing for site-independent crosslinking between one photoreactive ELP chain and any neighboring amino acid side chain ${ }^{[78]}$. To demonstrate the ability of photocrosslinking to create stable networks, ELP solutions were spin or dip coated onto Ti6Al4V substrates to create thin films prior to UV light exposure. Over three weeks of continuous washing at physiological conditions $\left(37^{\circ} \mathrm{C}, \mathrm{PBS}\right)$, the amount of protein in the processed films remained constant (Figure 1C). These data confirm that the photo-initiated reaction was successful at crosslinking the ELP into complete network. As expected, the cell-adhesive (RGD) and non-adhesive (scrambled) variants of our ELP resulted in stable films with similar amounts of protein and had no statistical differences in protein retention over time. 


\section{A}
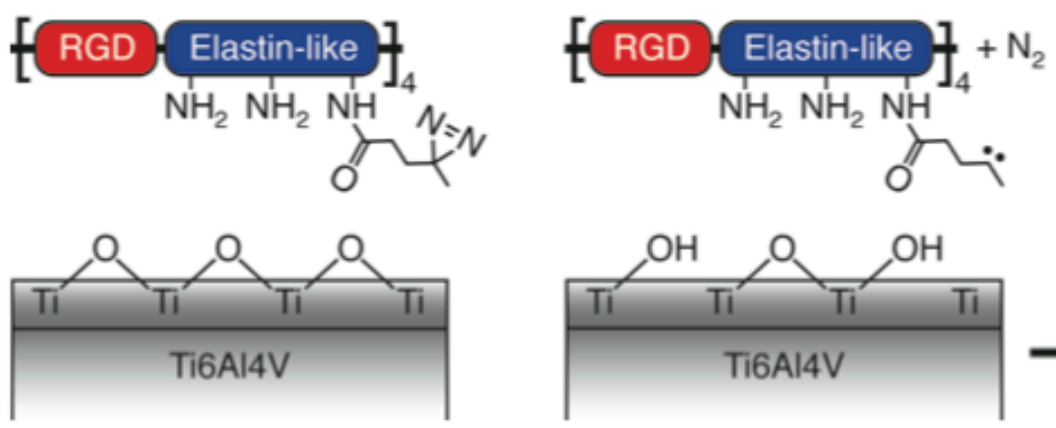

\section{RGD}

Elastin-like $\mathrm{NH}_{2} \mathrm{NH}_{2} \mathrm{NH}_{4}$

B
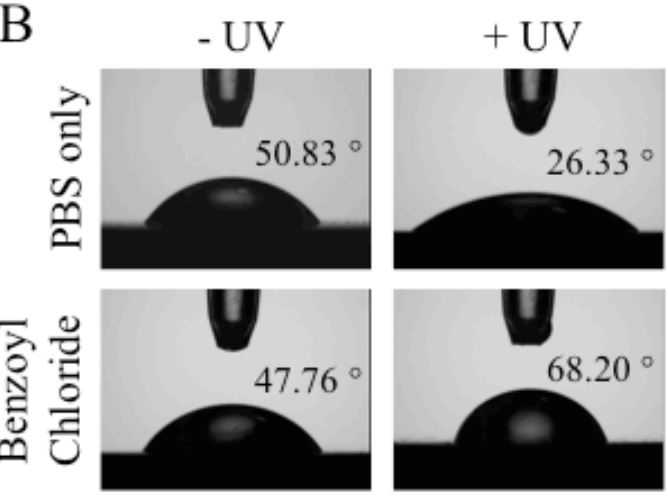

C
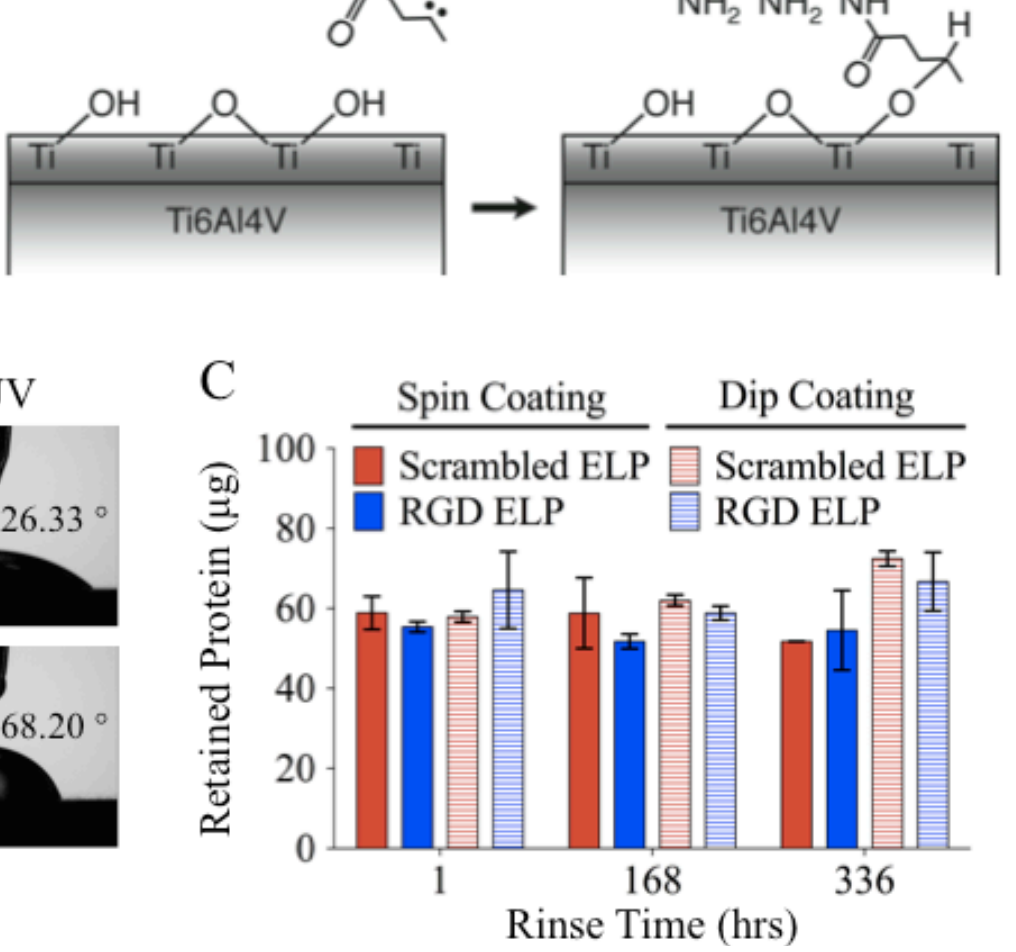

Figure 1. ELP processing to form a covalently crosslinked, thin film on titanium. A) Schematic of proposed ELP conjugation to titanium substrates upon exposure to UV light. B) Contact angle measurements of $\mathrm{H}_{2} \mathrm{O}$ on Ti6Al4V discs before and after PBS spin coating and UV exposure (top) and after exposure to $10 \%$ benzoyl chloride solution (bottom). C) Long-term passive stability of spin or dip coated ELP films of both scrambled and RGD variants.

Taken together, these data demonstrate that ELP can be processed in a straightforward manner to fabricate stable coatings on common implant materials. As opposed to many of the harsh solvents and processing conditions used for other types of orthopaedic coating deposition, which can alter the microstructure and integrity of the underlying implant or weaken and inactivate the coating itself $f^{[22,79-81]}$, our ELP coatings were deposited and crosslinked between $4{ }^{\circ} \mathrm{C}$ and room temperature. The facile and versatile processing of our ELP coatings using benign conditions suggests a straightforward pathway for clinical translation of the coating technology. Furthermore, the highly active nature of the carbene insertion mechanism suggests that this coating chemistry may be broadly applicable to a wide range of other coating/implant material combinations. 


\subsection{ELP Coatings can Withstand Procedures Mimicking Clinically Relevant Implantation Protocols}

Next we tested the ability of the ELP coatings to endure the types of clinical procedures used during implantation of dental screws and orthopaedic prostheses. Dental screws were spin coated with ELP and photocrosslinked prior to being screwed into a synthetic bone mimic, a polyurethane foam with a similar tensile modulus and compressive strength of the human mandible. ${ }^{[82,83]}$ The screws were then extracted, subjecting them to an additional shear stress. Screws were imaged via SEM before implantation and after extraction to characterize the presence and intactness of the ELP film. The thin, conformal ELP coating can be visualized along the threads of the screw, with a buildup of ELP on the inside of a thread (Figure 2A, arrowed). After screw removal, the ELP coating remained intact along the vast majority of the screw surface, which can be seen by comparing the pre- and post-implantation images of the surface (Figure 2A, top right and bottom left). An image of a rare defect in the coating is shown to contrast the continuous coating seen in other regions as well as to highlight the coating failure mode of peeling rather than flaking or cracking (Figure 2A, bottom right). These results suggest that photocrosslinked ELP coatings can remain intact during implantation, a critical prerequisite for later bioactive functionality at the implant site.

To demonstrate film stability during another common mode of device implantation, rods mimicking the stem portion of hip and knee prostheses were dip coated with ELP and press fit into the medullary cavity of mouse cadaver femurs. This model replicates key aspects of clinical press fitting of cementless implants, a common implantation method for hip replacements ${ }^{[84]}$. To evaluate the integrity of the ELP coating post-implantation, the ELP film was labeled with a fluorogenic probe. The majority (73\%) of the ELP film survived the insertion and extraction procedures (Figure 2B). Importantly, low and high magnification images of the implanted rods after extraction showed that the remaining coating was present along the entire length of the rod (Figure 2C). These results 
suggest that the ELP coatings have the potential to withstand implantation procedures similar to

those used clinically for the press fitting of orthopaedic implants and support future studies in larger animal models.

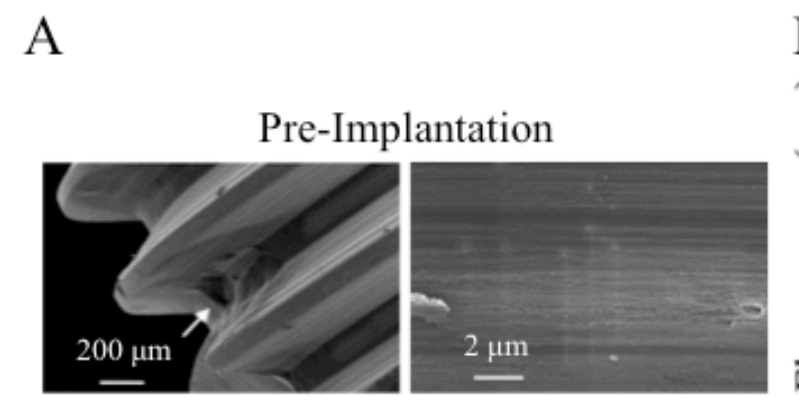

Post-Extraction
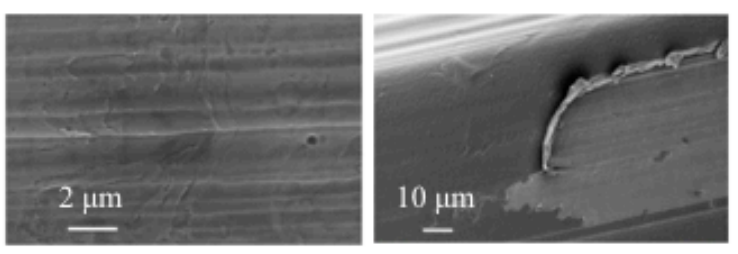

\section{$\mathrm{B}$}
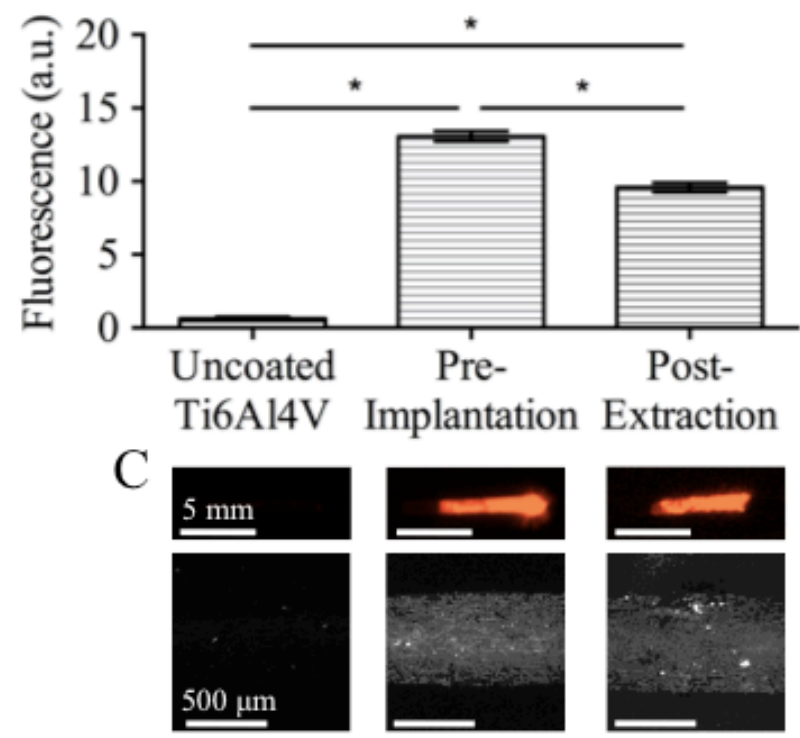

Figure 2. Active stability of ELP coatings on implants after clinically relevant implantation procedures. A) SEM of spin coated $\mathrm{cp}$-Ti dental screw pre-implantation and post-extraction from a mandible mimetic polyurethane foam block. The presence of a buildup of ELP is highlighted with a white arrow (top left). A small defect in the ELP film is shown post-implantation (bottom right). B) Mean fluorescence measurements of press fit Ti6Al4V rods dip coated in fluorescently-labeled ELP solution, $* \mathrm{p}<0.0001, \mathrm{n}=9$. C) Transilluminator (top) and fluorescence confocal microscopy (bottom) images of press fit Ti6A14V rods dip coated with fluorescently-labeled ELP solution.

\subsection{ELP Coatings Improve Osteoblast Adhesion and Mineralization}

After demonstrating the processability and strong adhesion of the coating to implant surfaces, we assessed the ability of the coating to facilitate key components of osseointegration in vitro. In particular, we looked at the efficacy of the coatings in promoting rapid adhesion, spreading and mineralization from MG63 osteoblast-like cells. Rapid bone mineral deposition on the implant surface is hypothesized to result in earlier stabilization of implants. ${ }^{\left[{ }^{[5]}\right.}$ MG63 cells spread significantly more rapidly on RGD ELP films that contained the cell-adhesive ligand compared to the negative-control, scrambled-sequence ELP coatings presented on glass coverslips (Figure 3A). 
Moreover, MG63s on RGD ELP coatings demonstrated more lamellipodia protrusions than cells on

scrambled ELP films, which appeared round and poorly adherent to the substrate (Figure 3B).

We next quantified MG63 adhesion to spin and dip coated ELP films on Ti6Al4V discs.

Cell adhesion was statistically improved after twenty-four hours for both spin and dip coated RGD ELP coatings ( $83 \%$ and $89 \%$, respectively) compared to uncoated Ti6Al4V (only 38\%) (Figure 3CD). Interestingly, elevated MG63 adhesion was seen after 24 hours on the scrambled ELP coatings relative to the bare Ti6Al4V. Presumably this increase is due to non-specific absorption of serum proteins onto the ELP coatings, consistent with previous studies of cell adhesion on ELP coatings at longer time points. ${ }^{[61,86-88]}$ The observed quantitative and morphological differences in MG63 at early time points suggests the potential for osteoblasts to begin depositing minerals rapidly on our RGD ELP coatings.

Calcium phosphate mineralization is an early-stage phenotypic marker of new bone formation. Calcium phosphates, particularly hydroxyapatite, are the main mineral component of bone tissue. To assess the potential for bone deposition on implant surfaces, calcium concentration was assayed in MG63 cultures seeded onto uncoated and coated Ti6A14V. By day 3 for both spin and dip coated substrates, RGD ELP had significantly higher calcium concentration than uncoated Ti6Al4V, a trend which continued through the two week study timecourse. Also at day 3 , the RGD ELP coating enabled significantly higher calcium deposition than the negative control, scrambled ELP variant. Elevated calcium deposition on the scrambled ELP coatings at later time points was again believed to be due to non-specific serum protein absorption, facilitating increased adhesion of MG63 cells and subsequent mineral deposition in osteogenic medium. At one week post-seeding, RGD ELP coated discs had more than two-fold higher calcium content than uncoated discs (Figure 3E-F). Notably, there was no significant difference in calcium content at any time point between the spin coated and dip coated RGD ELP samples, showing that both coating methods are equivalently well suited for inducing calcium mineral deposition. 


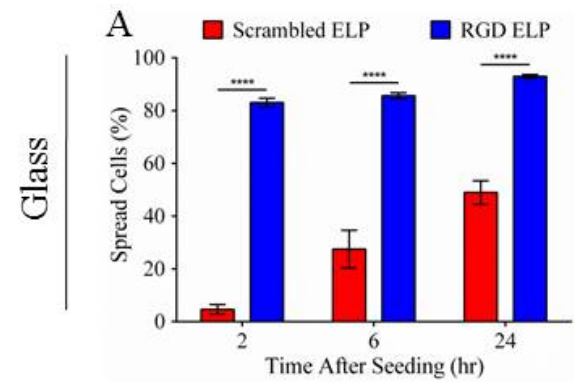

C

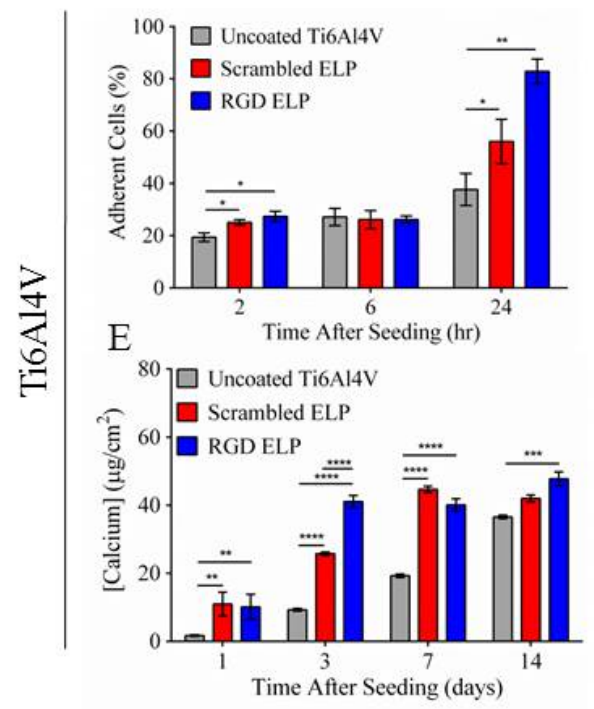

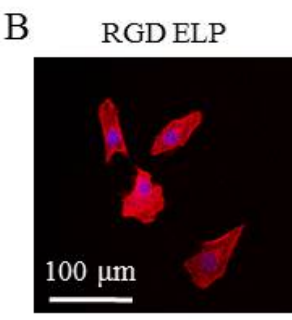

Scrambled ELP
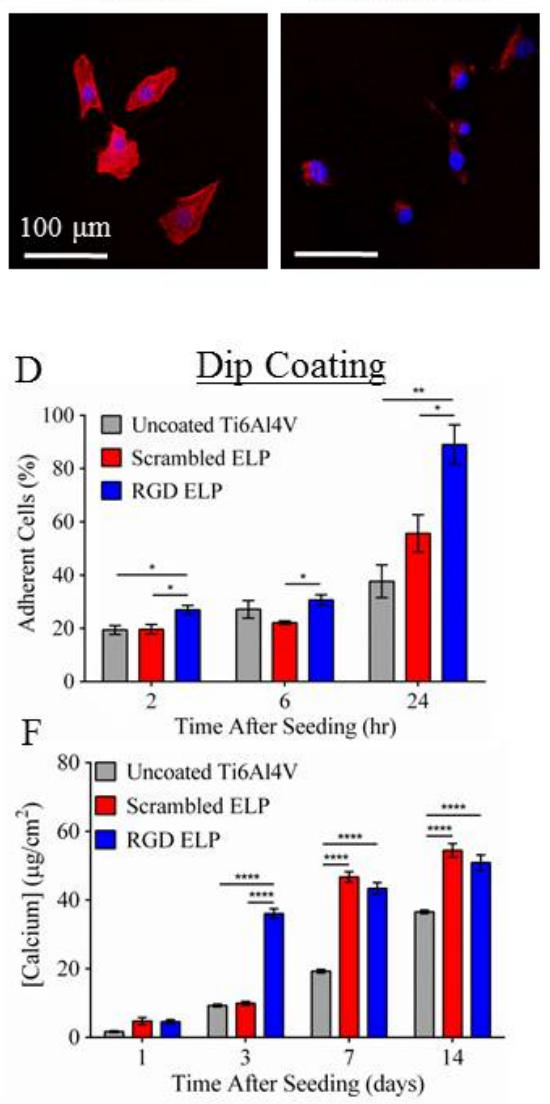

Figure 3. Spreading, adhesion and mineralization of MG63 cells seeded onto ELP coatings on glass and Ti6A14V. A) Spreading of MG63 cells onto scrambled ELP- and RGD ELP-coated glass substrates. B) Cell morphology and spreading of MG63 cells on scrambled ELP- and RGD ELPcoated glass. C\&D) Adhesion of MG63 cells on spin (C) and dip (D) coated Ti6Al4V over 24 hours. E\&F) Total MG63 calcium mineralization deposition on spin (E) and dip (F) coated Ti6Al4V over 14 days. $* \mathrm{p}<0.05, * * \mathrm{p}<0.01, * * * \mathrm{p}<0.001, * * * * \mathrm{p}<0.0001$.

Hydroxyapatite crystals in bone adopt an elongated, plate-like morphology. ${ }^{[89-91]}$ The dimensions of the plate-like minerals have reported lengths of 20-50 nm and thicknesses of a few nanometers. ${ }^{[90,92]}$ Therefore, we were interested not only in the amount of calcium deposited on our ELP coatings, but also in the morphology of the mineral crystals. Spin coated RGD ELP films seeded with MG63s were observed by SEM over two weeks. One day post-seeding, the MG63s on the RGD ELP appeared more aligned, elongated, and abundant than cells on the scrambled ELP and uncoated Ti6Al4V, matching the adhesion data previously reported (Figure 4). By day 7, the mineralization on the uncoated Ti6Al4V appeared to consist of small, nanometer-scale, spheres packed together into larger aggregates. The mineralization on the ELP coated samples was a combination of nanometer-scale spheres and larger, irregularly shaped particles on the order of tens 
of nanometers in size. By day 14, the morphology of the mineralization on the scrambled and RGD

ELP coatings clearly showed a more plate-like, blossoming, morphology. While the largest plate-

like crystals were on the order of $100 \mathrm{~nm}$ in length and $10 \mathrm{~nm}$ in thickness, the majority of these crystals had length scales of approximately $20 \mathrm{~nm}$ and thickness of approximately $2 \mathrm{~nm}$, matching the size order found in physiological hydroxyapatite crystals. These findings, combined with the increased amount of mineralization on ELP coated Ti6Al4V, suggest that these coatings may promote successful bone deposition for improved osseointegration.

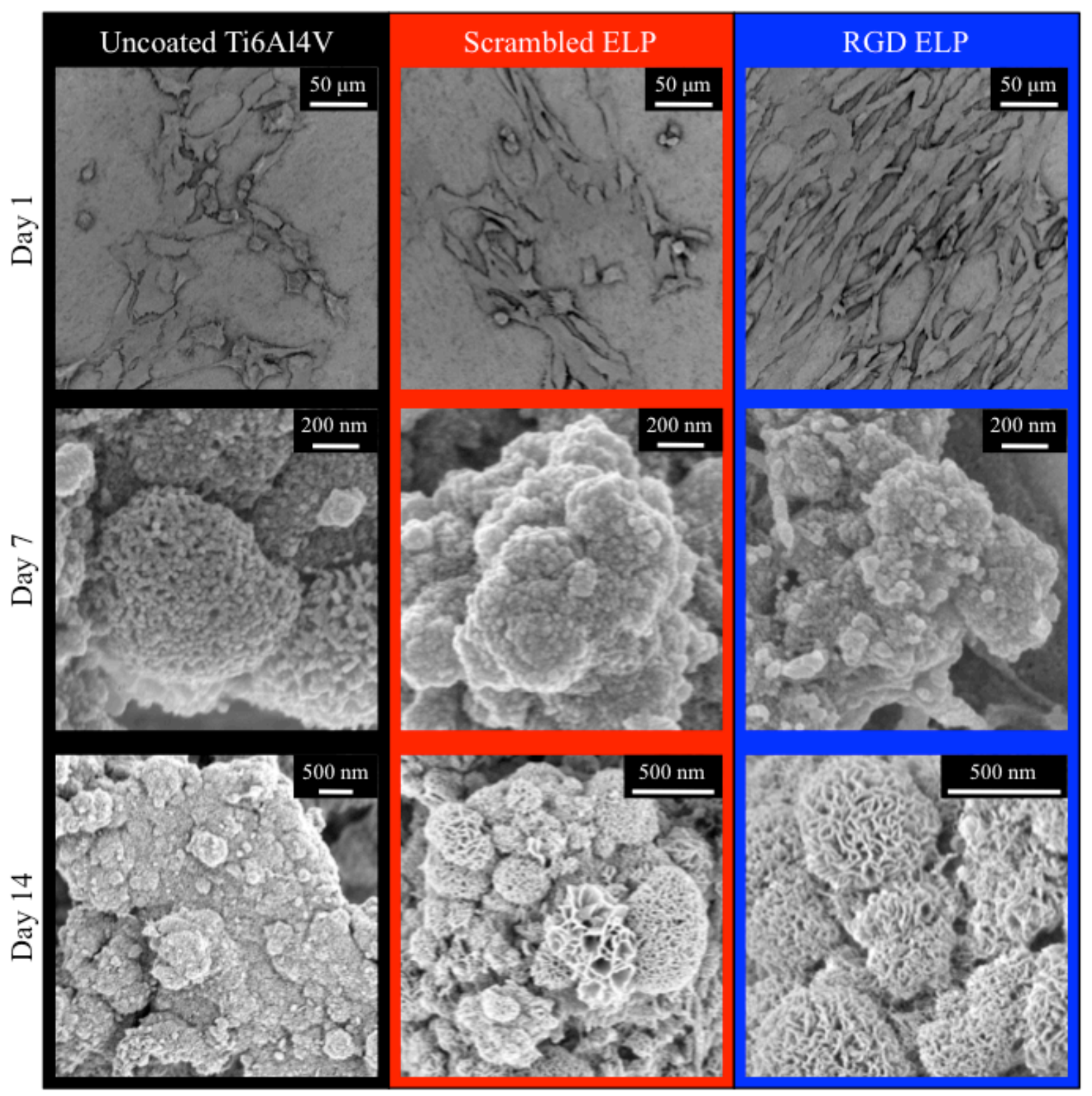

Figure 4. MG63 and mineralization morphology on uncoated, scrambled ELP, and RGD ELP spin coated Ti6A14V. SEM images were taken at 1, 7, and 14 days post-seeding of MG63s in mineralization medium (standard growth medium $+8 \mathrm{mM} \mathrm{CaCl}_{2}$ ). 


\subsection{ELP Coatings Enable Rapid Differentiation of Human Bone Marrow Mesenchymal Stem Cells}

\section{and Enhance Mineralization}

Implantation locations for dental and orthopaedic prostheses, such as the medullary cavity of the femur, are rich in the bone marrow subpopulation of mesenchymal stem cells. ${ }^{[93-96]}$ Mesenchymal stem cells are multipotent progenitor cells which have the capacity to differentiate down multiple cell lineages, including adipogenic, chondrogenic, and osteogenic lineages. ${ }^{\text {[97-101] }}$ They serve as the progenitor population for osteogenic cells during bone formation, remodeling, and fracture repair. ${ }^{[102]}$ As such, they have been studied extensively for use in bone tissue engineering applications. ${ }^{[61,103-106]}$ We assessed the ability of the ELP coatings to influence spreading, adhesion, osteogenic differentiation, and mineralization potential of human bone marrow-derived mesenchymal stem cells (hMSC) as a progenitor cell population that commonly interacts with dental and orthopaedic implants. hMSCs spread significantly faster and more completely to RGD ELP-coated glass, with $45 \%$ of cells exhibiting spreading after two hours and $90 \%$ at twenty-four hours compared to only $15 \%$ and $77 \%$ of cells on scrambled ELP-coated glass at those times, respectively (Figure 5A). As with MG63 cells, hMSCs on RGD ELP coated glass exhibited lamellipodia at 4 hours, while hMSCs on scrambled ELP-coated glass remained spherical (Figure 5B). This rapid spreading demonstrated the ability of the RGD ligand to induce binding of the clinically-relevant hMSCs to our coatings.

Interestingly, similar to the MG63 data (Figure 3C,D), adhesion of hMSCs onto uncoated titanium surfaces and ELP-coated titanium surfaces had no statistical differences at 6 hours (Figure 5C). Furthermore, at 24 hours, hMSC adhesion was significantly higher on uncoated titanium surfaces, demonstrating that non-specific adsorption of serum proteins is sufficient to induce cell adhesion. These data are consistent with previous reports of titanium fouling leading to hMSC adhesion. ${ }^{[61]}$ Nonetheless, statistical differences between the RGD ELP and scrambled ELP coatings at 2 hours and 24 hours demonstrates that the RGD domain is still available and active to cells, even in the presence of serum proteins. Thus, while not leading to enhanced hMSC adhesion 
in this context, the RGD ligand may still promote downstream signaling. Consistent with this notion,

at day 14, the amount of DNA per sample is significantly enhanced for RGD ELP-coated titanium relative to uncoated titanium or scrambled ELP coatings (Figure 5D). The RGD ligand is well known to promote proliferation of MSCs; thus, this enhancement in DNA is thought to reflect a faster rate of proliferation. ${ }^{[107,108]}$ The higher DNA content on scrambled ELP-coated titanium relative to uncoated titanium at time points between 10 and 28 days is presumably due to the nonspecific adsorption of serum proteins. These data are consistent with previous reports that the number of hMSCs on ELP coated-titanium between days 7 and 22 were statistically similar on coatings with and without the RGD ligand. ${ }^{[61]}$

The ability of hMSCs to deposit bone mineralization is dependent on them first differentiating down the osteogenic lineage. ${ }^{[102]}$ While many different biomarkers have been used to assess this differentiation at various stages, intracellular alkaline phosphatase (ALP) activity is one of the most widely employed metrics for mid-stage osteogenic differentiation. ${ }^{[109]}$ ALP activity was quantified relative to DNA concentration as an indicator of differentiation on a per cell basis. Thus, at day 3, when DNA concentration was at a low $\sim 5 \mathrm{ng}$, the normalized ALP activity was correspondingly high for all substrates tested (Figure 5D,E). When comparing the remaining time points, we find that ALP activity spikes for both ELP-coated titanium surfaces at day 7. In contrast, hMSCs seeded on bare titanium surfaces did not experience a spike in ALP activity until day 14 . Interestingly, no consistent differences in ALP activity were noted between the RGD ELP and scrambled ELP coatings, suggesting that signaling from fouling proteins may obscure the activity of the engineered RGD ligand. Previously, ALP levels have shown a characteristic spike between days 5 and 14 post-seeding during osteogenic differentiation, matching our observations. ${ }^{[98,110]}$ The presence of an early characteristic ALP spike is a strong indication of earlier osteogenic differentiation of hMSCs on our ELP coatings.

From day 10 onward, there was significantly more calcium on ELP coatings than the bare titanium control, culminating in a $45 \%$ increase in calcium content at 28 days (Figure 5F). This 
increase in mineralization correlated with a drop in alkaline phosphatase production, a trend that has

been widely established in the literature. ${ }^{[111,112]}$ As with ALP activity, no consistent differences in mineralization were noted between the RGD ELP and scrambled ELP coatings at the time points chosen. These data are similar to the results observed for MG63 mineralization at days 7 and 14, when both ELP coatings performed significantly better than bare titanium, but were not statistically different from each other (Figure 3E,F). Since the hMSCs must undergo differentiation down an osteogenic lineage prior to mineralization ${ }^{[111]}$, the delay in mineralization time compared with MG63s, which began depositing mineral almost immediately, was expected. For the MG63s, the largest differences in mineralization occurred at an early day 3 time point, when cells on RGD ELP coatings deposited four times as much calcium as cells on bare titanium as well as significantly outperformed cells on scrambled ELP coatings (Figure 3E,F). Thus, it is possible that additional time points for the hMSC assays may reveal more complex kinetic relationships between hMSC adhesion, proliferation, differentiation, and mineral deposition in response to the engineered RGD ligand, which may become fouled at later time points. Nevertheless, the ability of hMSCs and MG63s to produce significantly more early mineralization on ELP surfaces indicates these coatings may be beneficial for improved rapid osseointegration of orthopaedic and dental implants. 


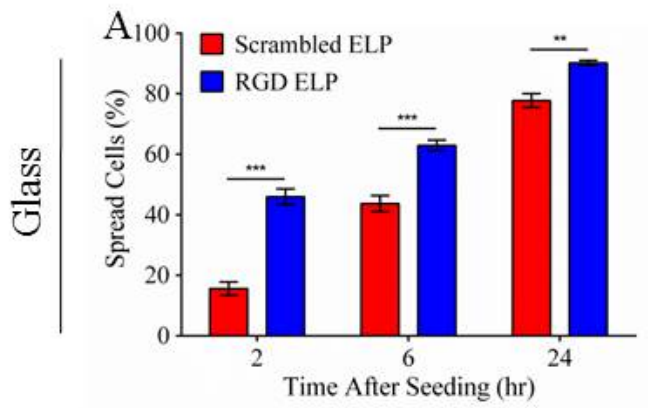

B

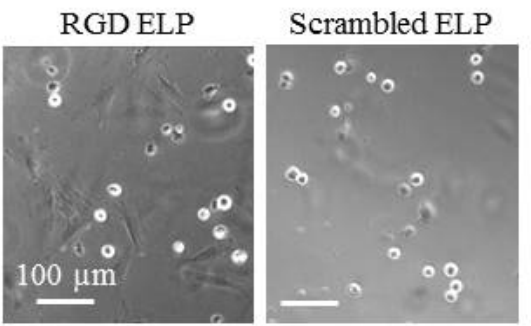

$\mathrm{C}$

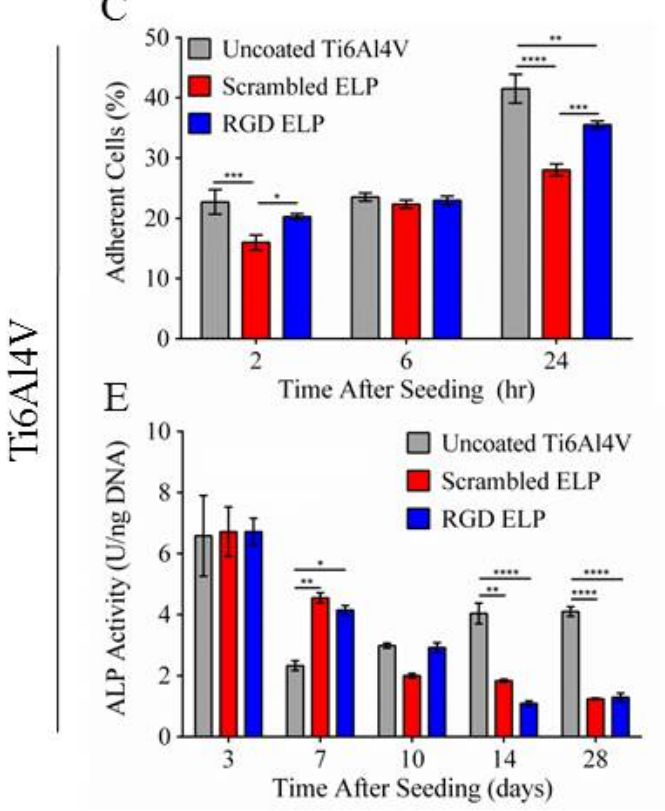

$\mathrm{D}$
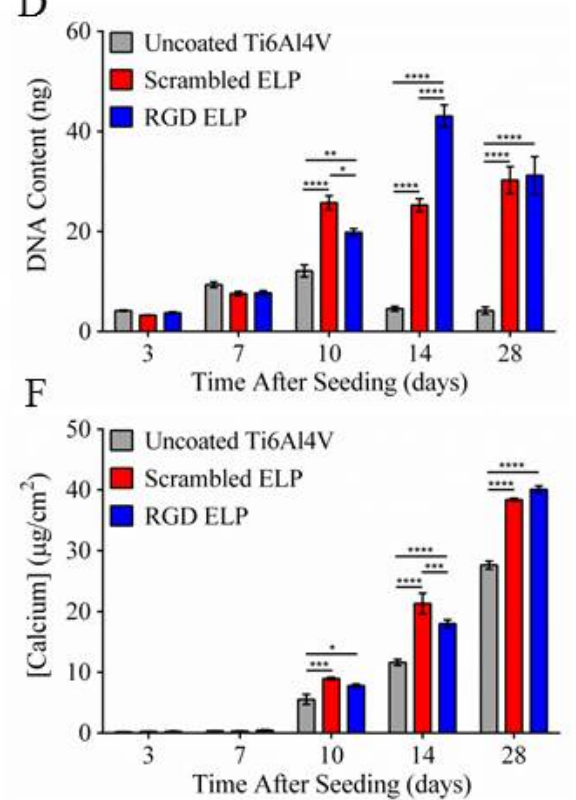

Figure 5. Spreading, adhesion and mineralization of hMSCs seeded onto ELP coatings on glass and Ti6Al4V. A) Spreading of hMSCs onto scrambled ELP- and RGD ELP-coated glass substrates. B) Representative phase contrast micrographs of hMSCs on scrambled ELP- and RGD ELP-coated glass at 4 hours. C) Adhesion of hMSCs on ELP-coated and bare Ti6Al4V over 24 hours. D-F) Total DNA concentration (D), ALP activity normalized to DNA concentration (E), and total calcium deposition (F) for hMSCs on ELP-coated and bare Ti6Al4V over 28 days. $* \mathrm{p}<0.05$, ** $\mathrm{p}<0.01, * * * \mathrm{p}<0.001, * * * * \mathrm{p}<0.0001$.

\subsection{ELP Coatings Improve Osseointegration and Bone Formation In Vivo}

To assess the potential of the ELP coatings to improve osseointegration in vivo, an animal study using ELP-coated cp-Ti dental screws implanted into rat tibia was performed. Three sample groups were included, RGD ELP, scrambled ELP, and uncoated Ti implants. All screws healed uneventfully and on the histological slides newly formed bone was observed around all implants.

The bone formed at the different implant surfaces was measured via bone-implant contact (BIC). After one week, mainly woven bone, intensely stained and with large osteocyte lacunae, filled the space between the implants surfaces and the osteotomy lines (Figure 6). In the statistical analysis of 
the histomorphometry results after one week, there was an overall main effect on the BIC. The

RGD ELP-coated screws had a statistically significant, $70 \%$ higher BIC than the scrambled ELPcoated samples. While there was a trend of an increased BIC for the RGD ELP-coated implants relative to uncoated Ti implants, including $45 \%$ greater BIC at one week, the difference was not significant for this given sample size $(\mathrm{n}=8)$.

These data support the hypothesis that RGD ligand-specific interactions can promote rapid bone mineralization, as the scrambled ELP coated samples were indistinguishable from bare titanium. At the longer healing times, the woven bone was substituted by mature bone, which showed a lamellar aspect after eight weeks. After four and eight weeks of healing, all three treatments had statistically similar BIC values, suggesting that the ELP coatings do not interfere with long-term osseointegration. This "catching up" in implant mineralization on the bare implant at later time points is commonly observed in other studies of implant surface functionalization, including the addition of bone morphogenetic proteins and other growth factors ${ }^{[113,114]}$ and coatings that employ nanoscale hydroxyapatite ${ }^{[115,116]}$ The significant increase in bone-implant contact area after one week of implantation may be very beneficial for addressing later-stage aseptic loosening of orthopaedic and dental prostheses. ${ }^{[117,118]}$ Indeed, the SLACtive surface, which has increased hydrophilicity and surface free energy, has resulted in improved clinical outcomes in dental applications, despite only improving bone-implant contact area at early stages of healing. ${ }^{[119-124]}$ The shortened healing time period enabled earlier implant loading with decreased risk of implant overloading. ${ }^{[123-126]}$ Thus, we propose that by improving the early-stage interface between the bone and implant surface through use of ELP coatings, micromotion may be decreased or eliminated during early implant loading. ${ }^{[127,128]}$ This reduction in micromotion may then lead to reduced longterm loosening and hence a lower premature revision rate for the implants. ${ }^{[14,15]}$ 
A

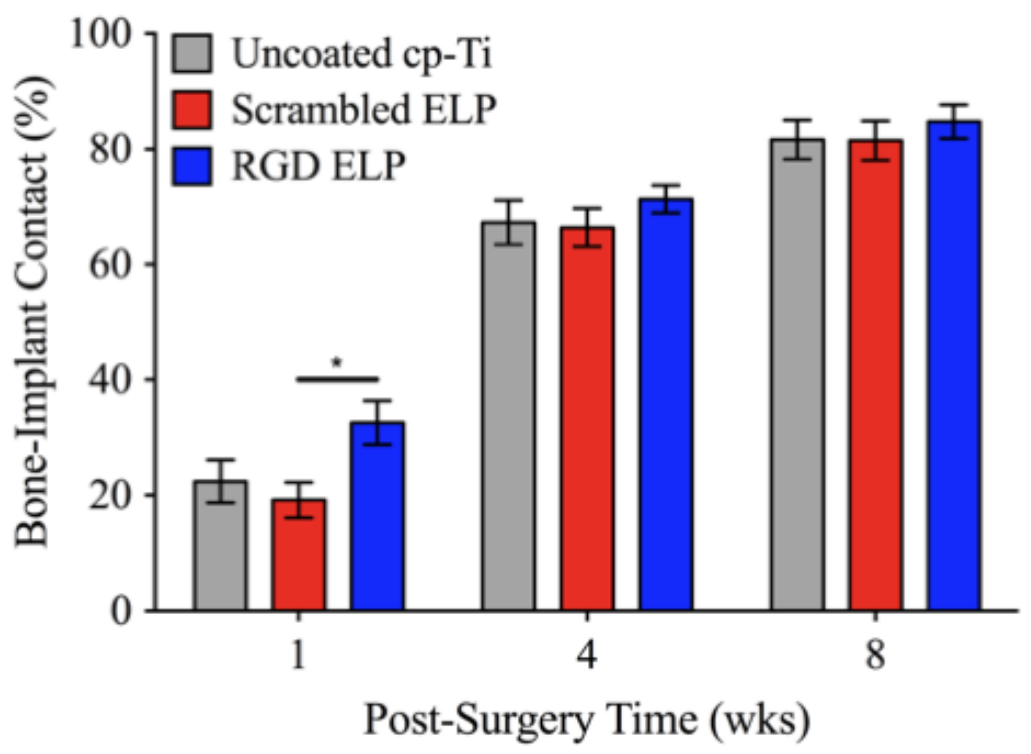

B
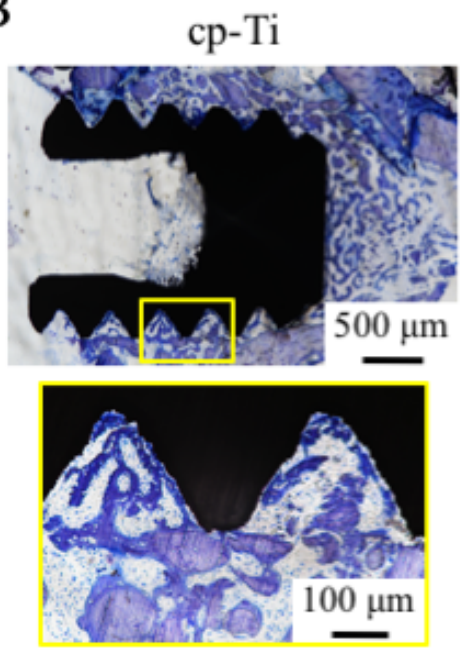

Scrambled ELP
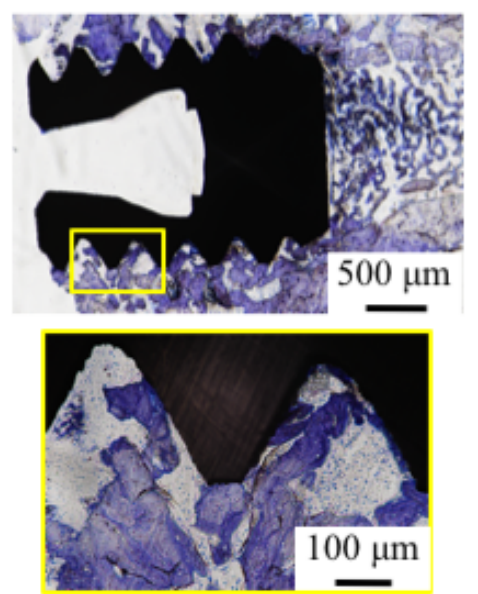

RGD ELP
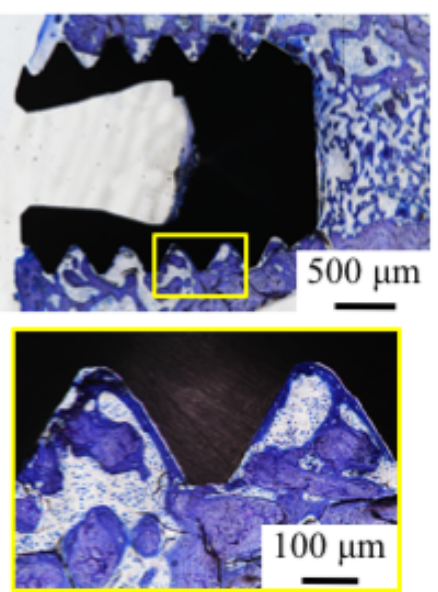

Figure 6. In vivo response to spin coated ELP films on cp-Ti dental screws implanted into rat femurs. A) Bone-implant contact (BIC) area quantification for ELP coated and uncoated dental screws over 8 weeks post-surgery. $n=8, * p<0.05$. B) Histological sections of inserted screws at 1 week (top). Expanded histological images of bone contact with screw threads for BIC area quantification (bottom). Section thickness $=20-30 \mu \mathrm{m}$. Toluidine blue staining.

Osseointegration was also measured using screw removal torque (RTQ) quantification

(Figure 7). The RTQ values confirmed the histomorphometrical results, as the RGD ELP group outperformed the other two groups after 1 week of healing. The interfacial bond between the RGD ELP and the bone, expressed by the strength necessary to break this bond, was $84 \%$ stronger than that of the uncoated Ti implants at 1 week, although the difference was not statistically significant for this sample size $(n=6, p=0.075)$. The average RTQ for the RGD ELP group was significantly 
higher than that of the scrambled ELP surfaces $(p=0.033)$, suggesting that rapid osseointegration

was due to the specific presence of the RGD ligand, which is consistent with the in vitro data. At 4 weeks, the RTQ values increased for all three test groups, testifying to the further development of osseointegration between the implant surfaces and the bone. However, at 8 weeks, only the ELPcoated samples continued to increase in RTQ, while the osseointegration of the Ti group remained stable between these two time points. This suggests the possibility of further improved osseointegration for the coated screws at longer time points due to a mechanism that does not require the RGD ligand.

Though the in vivo studies do not show a statistically significant improvement in BIC or RTQ using the RGD ELP coating relative to uncoated Ti implants, there is a trend of increased osseointegration metrics at one week. The ability of the coatings to withstand the implantation procedures and produce potential benefits early in the healing process make these coatings an interesting candidate for continued studies. Future efforts to iterate and improve the ELP coatings, in conjunction with larger in vivo studies, may lead to significant improvements.

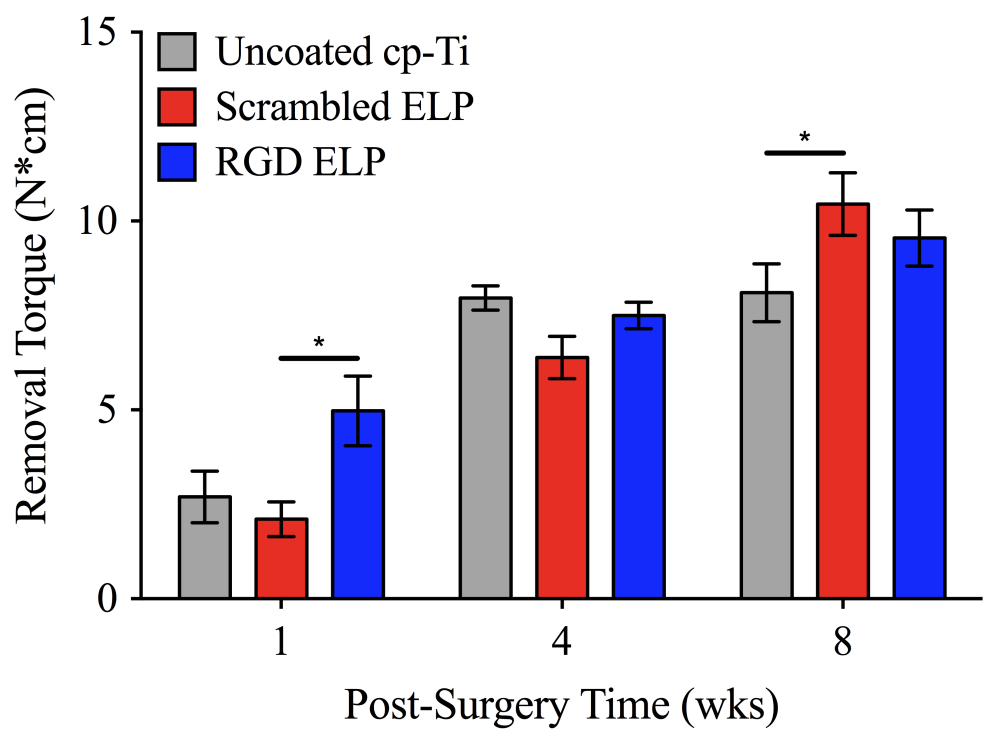

Figure 7. In vivo response to spin coated ELP films on cp-Ti dental screws implanted into rat femurs and tibias was tested using removal torque (RTQ) to measure the interfacial strength between the implant surfaces and peri-implant bone. Quantification extended over 8 weeks postsurgery; $\mathrm{n}=6$ at 1 week and $\mathrm{n}=8$ at weeks 4 and $8 ; * \mathrm{p}<0.05$. 


\section{Conclusion}

We have designed an engineered, photocrosslinkable, stable ELP coating to address the issue of aseptic loosening of dental and orthopaedic implants by increasing the speed of osseointegration of titanium implants. In order to achieve this goal, three primary requirements had to be met. First, the coating needed to be easily processable to be applied to a variety of implants. We demonstrated the ability to use aqueous spin and dip coat processing to make thin film coatings on cp-Ti and Ti6Al4V substrates, including discs, screws, and rods. Second, the coating needed to be stable to withstand implantation and daily wear. We confirmed a mechanism for direct conjugation of photocrosslinkable ELP to cp-Ti and Ti6Al4V surfaces mediated by UV light, resulting in a covalently crosslinked ELP network attached directly to the substrate surface via a carbene insertion mechanism. The ELP coatings remained intact in physiological conditions for three weeks and were able to withstand clinically related implantation procedures, a key step for potential clinical use that has not previously been demonstrated for these types of coatings. Finally, the coating needed to improve the rate of mineral deposition. Our ELP coatings enabled rapid adhesion of MG63 cells and hMSCs, induced differentiation of hMSCs down an osteogenic lineage, and increased mineral deposition from both cell types. Furthermore, the performed in vivo studies showed that implants coated with our RGD ELP coating significantly increased the bone-implant contact and interfacial strength compared to a scrambled ELP coating after one week of healing. The obtained result of enhanced bone formation at early time points is crucial to avoid the risk of aseptic loosening of bone-anchoring implants and it would enable earlier loading of the implant post-implantation. Combined, these results suggest that photocrosslinkable ELP coatings improve early-stage osseointegration of implants, which may lead to increased durability and reduction in the number of revision surgeries for aseptic loosening.

\section{Acknowledgements}


JR, JK, and SG contributed equally to this work. We thank Fort Wayne Metals for the Ti6Al4V

rods; Dr. Rebecca DiMarco for her assistance with SEM on dental screws; Dr. Jeffrey Tok and the Stanford Soft \& Hybrid Materials Facility (SMF) for experimental consultation and use of the profilometer and goniometer; Dr. Robert Beardsley Zeller for assistance in the design, fabrication, and programming of the dip coater; Dr. Jerome Geronimo and the Stanford 3-Dimensional Printing Facility for 3D printing of dip coater accessories; Dr. Lydia-Marie Joubert and the Beckman Cell Sciences Imaging Facility (CSIF) for assistance with and use of the SEM; and Dr. Patrick Benitez for assistance with endotoxin purification. We acknowledge funding from the Irish Research Council ELEVATE fellowship (MH), the Jane and Aatos Erkko Foundation (JP), the Wallenberg Foundation through the Wallenberg Academy Fellow Program (MA) and Materials Science an Area of Advance at Chalmers University of Technology, the National Science Foundation (DMR 0846363 to SCH), and the National Institutes of Health (2R01 AR055650, R01 063717 to SBG, U19 AI116484-01, R21 EB018407-01, R21 AR062359-01 to SCH).

[1] S. Kurtz, K. Ong, E. Lau, F. Mowat, and M. Halpern, "Projections of primary and revision hip and knee arthroplasty in the United States from 2005 to 2030", J. Bone Joint Surg. Am., 2007, 89, 780 .

[2] Milleniumresearchgroup. U.S. markets for dental implants, Available from: http://www.mrg.net/Products-and-Services/Syndicated-Report.aspx?r=RPUS22DE13 accessed: May, 2015.

[3] D. Schwartz-Arad, N. Kidron, and E. Dolev, "A long-term study of implants supporting overdentures as a model for implant success", J. Periodontol., 2005, 76, 1431.

[4] I. K. Karoussis, U. Bragger, G. E. Salvi, W. Burgin, and N. P. Lang, "Effect of implant design on survival and success rates of titanium oral implants: a 10-year prospective cohort study of the ITI Dental Implant System", Clin. Oral Implants Res., 2004, 15, 8. 
[5] L. W. Lindquist, G. E. Carlsson, and T. Jemt, "A prospective 15-year follow-up study of mandibular fixed prostheses supported by osseointegrated implants. Clinical results and marginal bone loss", Clin. Oral Implants Res., 1996, 7, 329.

[6] B. R. Chrcanovic, T. Albrektsson, and A. Wennerberg, "Reasons for failures of oral implants", J. Oral Rehabil., 2014, 41, 443.

[7] B. Pommer, S. Frantal, J. Willer, M. Posch, G. Watzek, and G. Tepper, "Impact of dental implant length on early failure rates: a meta-analysis of observational studies", J. Clin. Periodontol., 2011, 38, 856.

[8] K. T. Makela, M. Matilainen, P. Pulkkinen, A. M. Fenstad, L. Havelin, L. Engesaeter, et al., "Failure rate of cemented and uncemented total hip replacements: register study of combined Nordic database of four nations", BMJ, 2014, 348, f7592.

[9] S. Kurtz, F. Mowat, K. Ong, N. Chan, E. Lau, and M. Halpern, "Prevalence of primary and revision total hip and knee arthroplasty in the United States from 1990 through 2002", J. Bone Joint Surg. Am., 2005, 87, 1487.

[10] W. C. Schroer, K. R. Berend, A. V. Lombardi, C. L. Barnes, M. P. Bolognesi, M. E. Berend, et al., "Why are total knees failing today? Etiology of total knee revision in 2010 and 2011", J. Arthroplasty, 2013, 28, 116.

[11] D. F. Dalury, D. L. Pomeroy, R. S. Gorab, and M. J. Adams, "Why are total knee arthroplasties being revised?", J. Arthroplasty, 2013, 28, 120.

[12] J. C. Clohisy, G. Calvert, F. Tull, D. Mcdonald, and W. J. Maloney, "Reasons for revision hip surgery: a retrospective review", Clin. Orthop. Relat. Res., 2004, 188.

[13] S. Sakka, K. Baroudi, and M. Z. Nassani, "Factors associated with early and late failure of dental implants", J. Investig. Clin. Dent., 2012, 3, 258.

[14] M. Sundfeldt, L. V. Carlsson, C. B. Johansson, P. Thomsen, and C. Gretzer, "Aseptic loosening, not only a question of wear: a review of different theories", Acta Orthop. Scand., 2006, 77, 177. 
[15] S. B. Goodman, "The effects of micromotion and particulate materials on tissue differentiation. Bone chamber studies in rabbits", Acta Orthop. Scand. Suppl., 1994, 258, 1.

[16] X. Liu, and G. L. Niebur, "Bone ingrowth into a porous coated implant predicted by a mechano-regulatory tissue differentiation algorithm", Biomech. Model. Mechanobiol., 2008, 7,335 .

[17] L. Ryd, B. E. Albrektsson, L. Carlsson, F. Dansgard, P. Herberts, A. Lindstrand, et al., "Roentgen stereophotogrammetric analysis as a predictor of mechanical loosening of knee prostheses", J. Bone Joint Surg. Br., 1995, 77, 377.

[18] S. Szmukler-Moncler, H. Salama, Y. Reingewirtz, and J. H. Dubruille, "Timing of loading and effect of micromotion on bone-dental implant interface: review of experimental literature", J. Biomed. Mater. Res., 1998, 43, 192.

[19] X. Liu, P. K. Chu, and C. Ding, "Surface modification of titanium, titanium alloys, and related materials for biomedical applications", Mater. Sci. Eng. R, 2004, 47, 49.

[20] M. Long, and H. J. Rack, "Titanium alloys in total joint replacement--a materials science perspective", Biomaterials, 1998, 19, 1621.

[21] M. Niinomi, "Mechanical properties of biomedical titanium alloys", Mater. Sci. Eng. A, 1998, 243, 231.

[22] M. Geetha, A. K. Singh, R. Asokamani, and A. K. Gogia, "Ti based biomaterials, the ultimate choice for orthopaedic implants - a review", Prog. Mater. Sci., 2009, 54, 397.

[23] L. Le Guehennec, A. Soueidan, P. Layrolle, and Y. Amouriq, "Surface treatments of titanium dental implants for rapid osseointegration", Dent. Mater., 2007, 23, 844.

[24] H. Schliephake, and D. Schamweber, "Chemical and biological functionalization of titanium for dental implants", J. Mater. Chem., 2008, 18, 2404.

[25] S. B. Goodman, Z. Yao, M. Keeney, and F. Yang, "The future of biologic coatings for orthopaedic implants", Biomaterials, 2013, 34, 3174. 
[26] P. I. Branemark, P. Engstrand, L. O. Ohrnell, K. Grondahl, P. Nilsson, K. Hagberg, et al., "Branemark Novum: a new treatment concept for rehabilitation of the edentulous mandible. Preliminary results from a prospective clinical follow-up study", Clin. Implant Dent. Relat. Res., 1999, 1, 2.

[27] M. Esposito, M. G. Grusovin, H. Maghaireh, and H. V. Worthington, "Interventions for replacing missing teeth: different times for loading dental implants", Cochrane Database Syst. Rev., 2013, 3, CD003878.

[28] R. A. Berger, J. J. Jacobs, R. M. Meneghini, C. Della Valle, W. Paprosky, and A. G. Rosenberg, "Rapid rehabilitation and recovery with minimally invasive total hip arthroplasty", Clin. Orthop. Relat. Res., 2004, 239.

[29] K. R. Berend, A. V. Lombardi, Jr., and T. H. Mallory, "Rapid recovery protocol for perioperative care of total hip and total knee arthroplasty patients", Surg. Tech. Int., 2004, 13, 239.

[30] D. M. Ferris, G. D. Moodie, P. M. Dimond, C. W. Gioranni, M. G. Ehrlich, and R. F. Valentini, "RGD-coated titanium implants stimulate increased bone formation in vivo", Biomaterials, 1999, 20, 2323.

[31] H. Schliephake, D. Scharnweber, M. Dard, S. Rossler, A. Sewing, J. Meyer, et al., "Effect of RGD peptide coating of titanium implants on periimplant bone formation in the alveolar crest. An experimental pilot study in dogs", Clin. Oral Implants Res., 2002, 13, 312.

[32] R. Agarwal, C. Gonzalez-Garcia, B. Torstrick, R. E. Guldberg, M. Salmeron-Sanchez, and A. J. Garcia, "Simple coating with fibronectin fragment enhances stainless steel screw osseointegration in healthy and osteoporotic rats", Biomaterials, 2015, 63, 137.

[33] J. Raphel, A. Parisi-Amon, and S. Heilshorn, "Photoreactive elastin-like proteins for use as versatile bioactive materials and surface coatings", J. Mater. Chem., 2012, 22, 19429.

[34] S. R. Macewan, and A. Chilkoti, "Elastin-like polypeptides: biomedical applications of tunable biopolymers", Biopolymers, 2010, 94, 60. 
[35] D. W. Urry, "Physical Chemistry of Biological Free Energy Transduction As Demonstrated by Elastic Protein-Based Polymers", J. Phys. Chem. B, 1997, 101, 11007.

[36] D. W. Urry, "Molecular Machines: How Motion and Other Functions of Living Organisms Can Result from Reversible Chemical Changes", Angew. Chem. Int. Ed. Engl., 1993, 32, 819.

[37] A. Chilkoti, T. Christensen, and J. A. Mackay, "Stimulus responsive elastin biopolymers: Applications in medicine and biotechnology", Curr. Opin. Chem. Biol., 2006, 10, 652.

[38] D. Chow, M. L. Nunalee, D. W. Lim, A. J. Simnick, and A. Chilkoti, "Peptide-based Biopolymers in Biomedicine and Biotechnology", Mater. Sci. Eng. R-Rep., 2008, 62, 125.

[39] A. C. Rincon, I. T. Molina-Martinez, B. De Las Heras, M. Alonso, C. Bailez, J. C. Rodriguez-Cabello, et al., "Biocompatibility of elastin-like polymer poly(VPAVG) microparticles: in vitro and in vivo studies", J. Biomed. Mater. Res. A, 2006, 78, 343.

[40] R. E. Sallach, W. Cui, J. Wen, A. Martinez, V. P. Conticello, and E. L. Chaikof, "Elastinmimetic protein polymers capable of physical and chemical crosslinking", Biomaterials, 2009, 30, 409.

[41] S. C. Heilshorn, J. C. Liu, and D. A. Tirrell, "Cell-binding domain context affects cell behavior on engineered proteins", Biomacromolecules, 2005, 6, 318 .

[42] D. E. Meyer, and A. Chilkoti, "Purification of recombinant proteins by fusion with thermally-responsive polypeptides", Nat. Biotechnol., 1999, 17, 1112.

[43] C. M. Bellingham, M. A. Lillie, J. M. Gosline, G. M. Wright, B. C. Starcher, A. J. Bailey, et al., "Recombinant human elastin polypeptides self-assemble into biomaterials with elastinlike properties", Biopolymers, 2003, 70, 445.

[44] D. W. Urry, T. Hugel, M. Seitz, H. E. Gaub, L. Sheiba, J. Dea, et al., "Elastin: a representative ideal protein elastomer", Phil. Trans. R. Soc. B, 2002, 357, 169. 
[45] K. Trabbic-Carlson, L. A. Setton, and A. Chilkoti, "Swelling and mechanical behaviors of chemically cross-linked hydrogels of elastin-like polypeptides", Biomacromolecules, 2003, $4,572$.

[46] D. C. Chow, M. R. Dreher, K. Trabbic-Carlson, and A. Chilkoti, "Ultra-high expression of a thermally responsive recombinant fusion protein in E. coli", Biotechnol. Progr., 2006, 22, 638.

[47] I. Massodi, G. L. Bidwell, 3rd, and D. Raucher, "Evaluation of cell penetrating peptides fused to elastin-like polypeptide for drug delivery", J. Control. Release, 2005, 108, 396.

[48] J. R. Mcdaniel, D. J. Callahan, and A. Chilkoti, "Drug delivery to solid tumors by elastinlike polypeptides", Adv. Drug Deliv. Rev., 2010, 62, 1456.

[49] A. Girotti, J. Reguera, J. C. Rodriguez-Cabello, F. J. Arias, M. Alonso, and A. Matestera, "Design and bioproduction of a recombinant multi(bio)functional elastin-like protein polymer containing cell adhesion sequences for tissue engineering purposes", J. Mater. Sci. Mater. Med., 2004, 15, 479.

[50] P. C. Bessa, R. Machado, S. Nurnberger, D. Dopler, A. Banerjee, A. M. Cunha, et al., "Thermoresponsive self-assembled elastin-based nanoparticles for delivery of BMPs", $J$. Control. Release, 2010, 142, 312.

[51] Z. Megeed, J. Cappello, and H. Ghandehari, "Genetically engineered silk-elastinlike protein polymers for controlled drug delivery", Adv. Drug Deliv. Rev., 2002, 54, 1075.

[52] H. Betre, L. A. Setton, D. E. Meyer, and A. Chilkoti, "Characterization of a genetically engineered elastin-like polypeptide for cartilaginous tissue repair", Biomacromolecules, 2002, 3, 910 .

[53] M. K. Mchale, L. A. Setton, and A. Chilkoti, "Synthesis and in vitro evaluation of enzymatically cross-linked elastin-like polypeptide gels for cartilaginous tissue repair", Tissue Eng., 2005, 11, 1768. 
[54] D. L. Nettles, A. Chilkoti, and L. A. Setton, "Applications of elastin-like polypeptides in tissue engineering", Adv. Drug Deliv. Rev., 2010, 62, 1479.

[55] D. L. Nettles, K. Kitaoka, N. A. Hanson, C. M. Flahiff, B. A. Mata, E. W. Hsu, et al., "In situ crosslinking elastin-like polypeptide gels for application to articular cartilage repair in a goat osteochondral defect model", Tissue Eng. Part A, 2008, 14, 1133.

[56] S. C. Heilshorn, K. A. Dizio, E. R. Welsh, and D. A. Tirrell, "Endothelial cell adhesion to the fibronectin CS5 domain in artificial extracellular matrix proteins", Biomaterials, 2003, 24,4245 .

[57] H. Martinez-Osorio, M. Juarez-Campo, Y. Diebold, A. Girotti, M. Alonso, F. J. Arias, et al., "Genetically engineered elastin-like polymer as a substratum to culture cells from the ocular surface", Curr. Eye Res., 2009, 34, 48.

[58] A. V. Janorkar, P. Rajagopalan, M. L. Yarmush, and Z. Megeed, "The use of elastin-like polypeptide-polyelectrolyte complexes to control hepatocyte morphology and function in vitro", Biomaterials, 2008, 29, 625.

[59] E. Wang, S. H. Lee, and S. W. Lee, "Elastin-like polypeptide based hydroxyapatite bionanocomposites", Biomacromolecules, 2011, 12, 672.

[60] S. Prieto, A. Shkilnyy, C. Rumplasch, A. Ribeiro, F. J. Arias, J. C. Rodriguez-Cabello, et al., "Biomimetic calcium phosphate mineralization with multifunctional elastin-like recombinamers", Biomacromolecules, 2011, 12, 1480.

[61] E. Salvagni, G. Berguig, E. Engel, J. C. Rodriguez-Cabello, G. Coullerez, M. Textor, et al., "A bioactive elastin-like recombinamer reduces unspecific protein adsorption and enhances cell response on titanium surfaces", Colloids Surf., B, 2014, 114, 225.

[62] H. A. Klock, and J. Genzer, "Expanding the polymer mechanochemistry toolbox through surface-initiated polymerization", ACS Macro Lett., 2015, 4, 636.

[63] K. S. Straley, and S. C. Heilshorn, "Independent tuning of multiple biomaterial properties using protein engineering", Soft Matter, 2009, 5, 114. 
[64] M. Keeney, H. Waters, K. Barcay, X. Jiang, Z. Yao, J. Pajarinen, et al., "Mutant MCP-1 protein delivery from layer-by-layer coatings on orthopedic implants to modulate inflammatory response", Biomaterials, 2013, 34, 10287.

[65] Fda. Guidance for Industry: Pyrogen and Endotoxins Testing, Available from: http://www.fda.gov/drugs/guidancecomplianceregulatoryinformation/guidances/ucm314718 .htm\#_ftn27 accessed: June, 2015.

[66] L. E. Scriven, "Physics and applications of dip coating and spin coating", MRS Proc., 1988, 121,717 .

[67] G. Mendonca, D. B. Mendonca, F. J. Aragao, and L. F. Cooper, "Advancing dental implant surface technology--from micron- to nanotopography", Biomaterials, 2008, 29, 3822.

[68] S. W. Kweh, K. A. Khor, and P. Cheang, "An in vitro investigation of plasma sprayed hydroxyapatite (HA) coatings produced with flame-spheroidized feedstock", Biomaterials, 2002, 23, 775 .

[69] T. W. Bauer, R. C. Geesink, R. Zimmerman, and J. T. Mcmahon, "Hydroxyapatite-coated femoral stems. Histological analysis of components retrieved at autopsy", J. Bone Joint Surg. Am., 1991, 73, 1439.

[70] T. W. Bauer, "Hydroxyapatite: coating controversies", Orthopedics, 1995, 18, 885.

[71] R. D. Bloebaum, D. Beeks, L. D. Dorr, C. G. Savory, J. A. Dupont, and A. A. Hofmann, "Complications with hydroxyapatite particulate separation in total hip arthroplasty", Clin. Orthop. Relat. Res., 1994, 19.

[72] J. Gosline, M. Lillie, E. Carrington, P. Guerette, C. Ortlepp, and K. Savage, "Elastic proteins: biological roles and mechanical properties", Phil. Trans. R. Soc. B, 2002, 357, 121.

[73] H. Sigrist, A. Collioud, J. Clémence, H. Gao, R. Luginbuhl, M. Sanger, et al., "Surface immobilization of biomolecules by light", Opt. Eng., 1995, 34, 2339.

[74] H. Gao, M. Sanger, R. Luginbuhl, and H. Sigrist, "Immunosensing with photo-immobilized immunoreagents on planar optical wave guides", Biosens. Bioelectron., 1995, 10, 317. 
[75] N. Sakai, A. Fujishima, T. Watanabe, and K. Hashimoto, "Quantitative evaluation of the photoinduced hydrophilic conversion properties of $\mathrm{TiO} 2$ thin film surfaces by the reciprocal of contact angle", J. Phys. Chem. B, 2003, 107, 1028.

[76] H. Bayley, and J. R. Knowles, "Photogenerated reagents for membrane labeling. 1. Phenylnitrene formed within the lipid bilayer", Biochemistry, 1978, 17, 2414.

[77] A. Sinz, "Chemical cross-linking and mass spectrometry to map three-dimensional protein structures and protein-protein interactions", Mass Spectrom. Rev., 2006, 25, 663.

[78] H. Sigrist, M. Mühlemann, and M. Dolder, "Philicty of amino acid side-chains for photogenerated carbenes", J. Photochem. Photobiol., B, 1990, 7, 277.

[79] B. G. Zhang, D. E. Myers, G. G. Wallace, M. Brandt, and P. F. Choong, "Bioactive coatings for orthopaedic implants-recent trends in development of implant coatings", Int. J. Mol. Sci., 2014, 15, 11878.

[80] J. E. Hulshoff, T. Hayakawa, K. Van Dijk, A. F. Leijdekkers-Govers, J. P. Van Der Waerden, and J. A. Jansen, "Mechanical and histologic evaluation of Ca-P plasma-spray and magnetron sputter-coated implants in trabecular bone of the goat", J. Biomed. Mater. Res., 1997, 36, 75 .

[81] H. Wang, N. Eliaz, Z. Xiang, H. P. Hsu, M. Spector, and L. W. Hobbs, "Early bone apposition in vivo on plasma-sprayed and electrochemically deposited hydroxyapatite coatings on titanium alloy", Biomaterials, 2006, 27, 4192.

[82] C. E. Misch, Z. Qu, and M. W. Bidez, "Mechanical properties of trabecular bone in the human mandible: implications for dental implant treatment planning and surgical placement", J. Oral Maxillofac. Surg., 1999, 57, 700.

[83] Sawbones. Biomechanical Test Materials Properties, Available from: http://www.sawbones.com/UserFiles/Docs/biomechanical_catalog.pdf accessed: June, 2015. 
[84] M. Pennington, R. Grieve, J. S. Sekhon, P. Gregg, N. Black, and J. H. Van Der Meulen, "Cemented, cementless, and hybrid prostheses for total hip replacement: cost effectiveness analysis", BMJ, 2013, 346, f1026.

[85] A. J. Garcia, and C. D. Reyes, "Bio-adhesive surfaces to promote osteoblast differentiation and bone formation", J. Dent. Res., 2005, 84, 407.

[86] J. C. Liu, S. C. Heilshorn, and D. A. Tirrell, "Comparative cell response to artificial extracellular matrix proteins containing the RGD and CS5 cell-binding domains", Biomacromolecules, 2004, 5, 497.

[87] J. C. Liu, and D. A. Tirrell, "Cell response to RGD density in cross-linked artificial extracellular matrix protein films", Biomacromolecules, 2008, 9, 2984.

[88] S. Ravi, J. M. Caves, A. W. Martinez, C. A. Haller, and E. L. Chaikof, "Incorporation of fibronectin to enhance cytocompatibility in multilayer elastin-like protein scaffolds for tissue engineering", J. Biomed. Mater. Res. A, 2013, 101, 1915.

[89] S. Weiner, and W. Traub, "Organization of hydroxyapatite crystals within collagen fibrils", FEBS Lett., 1986, 206, 262.

[90] S. Weiner, and W. Traub, "Bone structure: from angstroms to microns", FASEB J., 1992, 6, 879.

[91] J. Y. Rho, L. Kuhn-Spearing, and P. Zioupos, "Mechanical properties and the hierarchical structure of bone", Med. Eng. Phys., 1998, 20, 92.

[92] B. Clarke, "Normal bone anatomy and physiology", Clin. J. Am. Soc. Nephrol., 2008, 3 Suppl 3, S131.

[93] J. E. Davies, "Mechanisms of endosseous integration", Int. J. Prosthodont., 1998, 11, 391.

[94] R. W. Bucholz, "Nonallograft osteoconductive bone graft substitutes", Clin. Orthop. Relat. Res., 2002, 44. 
[95] G. T. Huang, S. Gronthos, and S. Shi, "Mesenchymal stem cells derived from dental tissues vs. those from other sources: their biology and role in regenerative medicine", J. Dent. Res., 2009, $88,792$.

[96] J. I. Ahn, S. Terry Canale, S. D. Butler, and K. A. Hasty, "Stem cell repair of physeal cartilage", J. Orthop. Res., 2004, 22, 1215.

[97] A. I. Caplan, "Mesenchymal stem cells", J. Orthop. Res., 1991, 9, 641.

[98] M. F. Pittenger, A. M. Mackay, S. C. Beck, R. K. Jaiswal, R. Douglas, J. D. Mosca, et al., "Multilineage potential of adult human mesenchymal stem cells", Science, 1999, 284, 143.

[99] D. J. Prockop, "Marrow stromal cells as stem cells for nonhematopoietic tissues", Science, 1997, $276,71$.

[100] J. N. Beresford, J. H. Bennett, C. Devlin, P. S. Leboy, and M. E. Owen, "Evidence for an inverse relationship between the differentiation of adipocytic and osteogenic cells in rat marrow stromal cell cultures", J. Cell Sci., 1992, 102 ( Pt 2), 341.

[101] J. U. Yoo, T. S. Barthel, K. Nishimura, L. Solchaga, A. I. Caplan, V. M. Goldberg, et al., "The chondrogenic potential of human bone-marrow-derived mesenchymal progenitor cells", J. Bone Joint Surg. Am., 1998, 80, 1745.

[102] S. P. Bruder, D. J. Fink, and A. I. Caplan, "Mesenchymal stem cells in bone development, bone repair, and skeletal regeneration therapy", J. Cell. Biochem., 1994, 56, 283.

[103] J. R. Mauney, V. Volloch, and D. L. Kaplan, "Role of adult mesenchymal stem cells in bone tissue engineering applications: current status and future prospects", Tissue Eng., 2005, 11, 787.

[104] A. I. Caplan, "Review: mesenchymal stem cells: cell-based reconstructive therapy in orthopedics", Tissue Eng., 2005, 11, 1198.

[105] R. S. Tuan, G. Boland, and R. Tuli, "Adult mesenchymal stem cells and cell-based tissue engineering", Arthritis. Res. Ther., 2003, 5, 32. 
[106] R. S. Tuan, "Role of adult stem/progenitor cells in osseointegration and implant loosening", Int. J. Oral Maxillofac. Implants, 2011, 26 Suppl, 50.

[107] J. J. Schmidt, J. Jeong, and H. Kong, "The interplay between cell adhesion cues and curvature of cell adherent alginate microgels in multipotent stem cell culture", Tissue Eng. Part A, 2011, 17, 2687.

[108] I. L. Kim, S. Khetan, B. M. Baker, C. S. Chen, and J. A. Burdick, "Fibrous hyaluronic acid hydrogels that direct MSC chondrogenesis through mechanical and adhesive cues", Biomaterials, 2013, 34, 5571.

[109] M. C. Vemuri, L. G. Chase, and M. S. Rao, "Mesenchymal stem cell assays and applications", Methods Mol. Biol., 2011, 698, 3.

[110] J. E. Aubin, "Regulation of osteoblast formation and function", Rev. Endocr. Metab. Disord., 2001, 2,81 .

[111] N. Jaiswal, S. E. Haynesworth, A. I. Caplan, and S. P. Bruder, "Osteogenic differentiation of purified, culture-expanded human mesenchymal stem cells in vitro", J. Cell. Biochem., 1997, $64,295$.

[112] B. Genge, G. Sauer, L. Wu, F. Mclean, and R. Wuthier, "Correlation between loss of alkaline phosphatase activity and accumulation of calcium during matrix vesicle-mediated mineralization", J. Bio. Chem., 1988, 263, 18513.

[113] J. J. Yoo, Y. J. Park, S. H. Rhee, H. J. Chun, and H. J. Kim, "Synthetic peptide-conjugated titanium alloy for enhanced bone formation in vivo", Connect. Tis. Res., 2012, 53, 359.

[114] M. Ramazanoglu, R. Lutz, C. Ergun, C. Von Wilmowsky, E. Nkenke, and K. A. Schlegel, "The effect of combined delivery of recombinant human bone morphogenetic protein-2 and recombinant human vascular endothelial growth factor 165 from biomimetic calciumphosphate-coated implants on osseointegration", Clin. Oral Implants Res., 2011, 22, 1433. 
[115] M. S. Bryington, M. Hayashi, Y. Kozai, S. Vandeweghe, M. Andersson, A. Wennerberg, et

al., "The influence of nano hydroxyapatite coating on osseointegration after extended healing periods", Dent. Mater., 2013, 29, 514.

[116] L. Melin Svanborg, L. Meirelles, V. Franke Stenport, P. Kjellin, F. Currie, M. Andersson, et al., "Evaluation of bone healing on sandblasted and Acid etched implants coated with nanocrystalline hydroxyapatite: an in vivo study in rabbit femur", Int. J. Dent., 2014, 2014.

[117] F. Marco, F. Milena, G. Gianluca, and O. Vittoria, "Peri-implant osteogenesis in health and osteoporosis", Micron, 2005, 36, 630.

[118] M. A. Freeman, and P. Plante-Bordeneuve, "Early migration and late aseptic failure of proximal femoral prostheses", J. Bone Joint Surg. Br., 1994, 76, 432.

[119] S. Sista, C. Wen, P. D. Hodgson, and G. Pande, "The influence of surface energy of titanium-zirconium alloy on osteoblast cell functions in vitro", J. Biomed. Mater. Res. A, 2011, 97, 27.

[120] B. S. Kopf, S. Ruch, S. Berner, N. D. Spencer, and K. Maniura-Weber, "The role of nanostructures and hydrophilicity in osseointegration: In-vitro protein-adsorption and bloodinteraction studies", J. Biomed. Mater. Res. A, 2015, 103, 2661.

[121] D. Buser, N. Broggini, M. Wieland, R. K. Schenk, A. J. Denzer, D. L. Cochran, et al., "Enhanced bone apposition to a chemically modified SLA titanium surface", J. Dent. Res., 2004, 83, 529 .

[122] M. M. Bornstein, P. Valderrama, A. A. Jones, T. G. Wilson, R. Seibl, and D. L. Cochran, "Bone apposition around two different sandblasted and acid-etched titanium implant surfaces: a histomorphometric study in canine mandibles", Clin. Oral Implants Res., 2008, 19, 233.

[123] T. W. Oates, P. Valderrama, M. Bischof, R. Nedir, A. Jones, J. Simpson, et al., "Enhanced implant stability with a chemically modified SLA surface: a randomized pilot study", Int. J. Oral Maxillofac. Implants, 2007, 22, 755. 
[124] N. P. Lang, G. E. Salvi, G. Huynh-Ba, S. Ivanovski, N. Donos, and D. D. Bosshardt, "Early osseointegration to hydrophilic and hydrophobic implant surfaces in humans", Clin. Oral Implants Res., 2011, 22, 349.

[125] M. Schatzle, R. Mannchen, U. Balbach, C. H. Hammerle, H. Toutenburg, and R. E. Jung, "Stability change of chemically modified sandblasted/acid-etched titanium palatal implants. A randomized-controlled clinical trial", Clin. Oral Implants Res., 2009, 20, 489.

[126] P. Valderrama, T. W. Oates, A. A. Jones, J. Simpson, J. D. Schoolfield, and D. L. Cochran, "Evaluation of two different resonance frequency devices to detect implant stability: a clinical trial", J. Periodontol., 2007, 78, 262.

[127] H. Kienapfel, C. Sprey, A. Wilke, and P. Griss, "Implant fixation by bone ingrowth", $J$. Arthroplasty, 1999, 14, 355.

[128] Y. Abu-Amer, I. Darwech, and J. C. Clohisy, "Aseptic loosening of total joint replacements: mechanisms underlying osteolysis and potential therapies", Arthritis. Res. Ther., 2007, 9 Suppl 1, S6. 